San Jose State University

SJSU ScholarWorks

Master's Theses

Master's Theses and Graduate Research

1992

\title{
A Study to determine the relevance of didactic assignments to the educational goals of Level II Fieldwork and the current use of didactic assignments by fieldwork settings
}

Karin Boyce Hull

San Jose State University

Follow this and additional works at: https://scholarworks.sjsu.edu/etd_theses

\section{Recommended Citation}

Hull, Karin Boyce, "A Study to determine the relevance of didactic assignments to the educational goals of Level II Fieldwork and the current use of didactic assignments by fieldwork settings" (1992). Master's Theses. 470.

DOI: https://doi.org/10.31979/etd.evp6-jhvj

https://scholarworks.sjsu.edu/etd_theses/470

This Thesis is brought to you for free and open access by the Master's Theses and Graduate Research at SJSU ScholarWorks. It has been accepted for inclusion in Master's Theses by an authorized administrator of SJSU ScholarWorks. For more information, please contact scholarworks@sjsu.edu. 


\section{INFORMATION TO USERS}

This manuscript has been reproduced from the microfilm master. UMI films the text directly from the original or copy submitted. Thus, some thesis and dissertation copies are in typewriter face, while others may be from any type of computer printer.

The quality of this reproduction is dependent upon the quality of the copy submitted. Broken or indistinct print, colored or poor quality illustrations and photographs, print bleedthrough, substandard margins, and improper alignment can adversely affect reproduction.

In the unlikely event that the author did not send UMI a complete manuscript and there are missing pages, these will be noted. Also, if unauthorized copyright material had to be removed, a note will indicate the deletion.

Oversize materials (e.g., maps, drawings, charts) are reproduced by sectioning the original, beginning at the upper left-hand corner and continuing from left to right in equal sections with small overlaps. Each original is also photographed in one exposure and is included in reduced form at the back of the book.

Photographs included in the original manuscript have been reproduced xerographically in this copy. Higher quality $6 "$ " 9 9" black and white photographic prints are available for any photographs or illustrations appearing in this copy for an additional charge. Contact UMI directly to order.

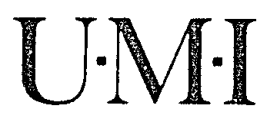

University Microfilms Internatıonal 

Order Number 1351041

A study to determine the relevance of didactic assignments to the educational goals of Level II Fieldwork and the current use of didactic assignments by fieldwork settings

Hull, Karin Boyce, M.S.

San Jose State University, 1992

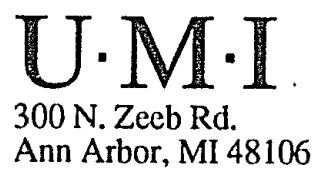





\title{
A STUDY TO DETERMINE THE RELEVANCE OF DIDACTIC ASSIGNMENTS TO THE EDUCATIONAL GOALS OF LEVEL II FIELDWORK AND THE CURRENT USE OF DIDACTIC ASSIGNMENTS BY FIELDWORK SETTINGS
}

\author{
A Thesis \\ Presented to \\ The Faculty of the Department of Occupational Therapy \\ San Jose State University \\ In Partial Fufillment \\ of the Requirements for the Degree \\ Master of Science
}

By

Karin Boyce Hull

December, 1992 
APPROVED FOR THE DEPARTMENT OF OCCUPATIONAL THERAPY

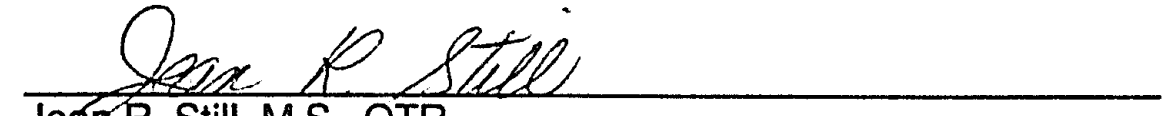
JeanR. Still, M.S., OTR

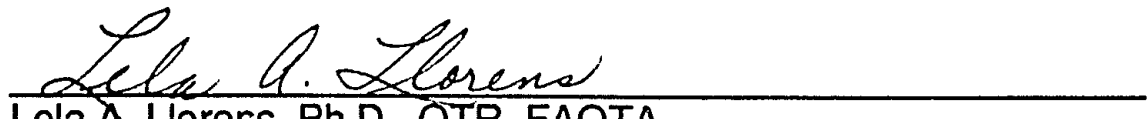
Lela A Lloreris, Ph.D., OTR, FAOTA

Toun Aernatu OTK Louise Sumpter, OTR

APPROVED FOR THE UNIVERSITY

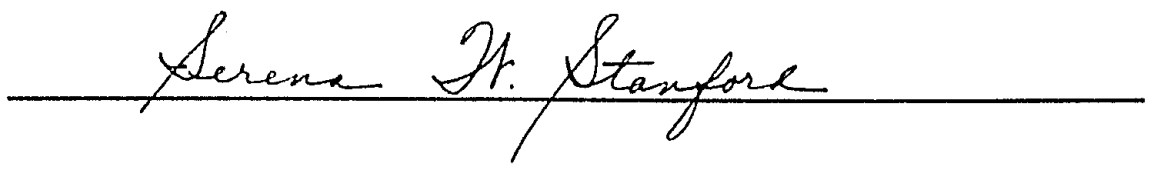




\begin{abstract}
A STUDY TO DETERMINE THE RELEVANCE OF DIDACTIC ASSIGNMENTS TO THE EDUCATIONAL GOALS OF LEVEL II FIELDWORK AND THE CURPRENT USE OF DIDACTIC ASSIGNMENTS BY FIELDWORK SETTINGS by Karin Boyce Hull

The objectives of this study were to obtain information about didactic assignments or learning experiences required of Level II Fieldwork students in occupational therapy, including type, variation, and purpose. The study also sought to determine the relevance of assignments to the goals of fieldwork. Survey methodology was utilized with questionnaires sent to Level II Fieldwork facilities in California having an affiliation with the San Jose State University Department of Occupational Therapy. One hundred and twelve questionnaires (70\%) were returned with valid data and were analyzed with descriptive statistics.

Data indicate facilities utilize a wide variety of assignments. Direct patient related tasks were used most consistently and frequently for the purposes of developing treatment skills and problem solving as well as data collection and communication skills. There was greater variety in the type and number of required indirect service assignments and enabling assignments. Supervisory and administrative assignments were used least. The results provide an overview of didactic assignments used in fieldwork and could be used as a basis to explore this and related areas of fieldwork education.
\end{abstract}




\section{ACKNOWLEDGEMENTS}

I wish to express my sincere appreciation to all those who have helped me throughout the thesis process. This could not have been accomplished without their support and assistance, which continued through the many months at each stage of the thesis, and through several concurrent significant events and changes in my life.

I would especially like to thank my thesis committee. To Jean R. Still, M.S., OTR, much appreciation for her knowledge, guidance, support, and perseverance. Her expertise and involvement in fieldwork education provided the initial inspiration for the study. Special thanks also to Lela A. Llorens, Ph.D., OTR, FAOTA, for sharing her time, knowledge, guidance, and becoming my advisor upon Jean Still's retirement, and to Louise Sumpter, OTR, for her time, feedback, and advice.

Thank you also to those who took time from their busy schedules to help provide initial feedback and advice on the questionnaire. I would like to thank David Gross for his assistance with the statistical analysis and presentation of the data.

Further, special thanks are given to my friend Kristin Syms, M.S., OTR, for her encouragement, support, advice, and inspiration.

Finally I wish to thank my family, and most of all my husband, John, for his tremendous support, love, encouragement, and faith. 


\section{TABLE OF CONTENTS}

ABSTRACT iii

ACKNOWLEDGEMENTS iv

LIST OF TABLES vii

CHAPTER 1. INTRODUCTION

Purpose

Statement of the Problem 1

Objectives 3

Questions 4

Definitions 5

Assumptions $\quad 6$

Limitations $\quad 7$

$\begin{array}{ll}\text { Significance of the Study } & 7\end{array}$

CHAPTER 2. LITERATURE REVIEW 10

Overview 10

History of Occupational Therapy Fieldwork Education 10

Purpose of Fieldwork $\quad 15$

$\begin{array}{ll}\text { Student Learning } & 18\end{array}$

Clinical Teaching and Supervision 20

Frame of Reference $\quad 26$

$\begin{array}{ll}\text { Summary } & 27\end{array}$

CHAPTER 3. DESIGN AND METHODOLOGY 29

Purpose and Objectives $\quad 29$

Questions 30

Subjects 31

Procedure $\quad 31$

Data Analysis $\quad 32$

CHAPTER 4. DATA AND RESULTS 34

Demographic Data $\quad 34$

Research Questions $\quad 37$

Question One $\quad 37$

Question Two 38

Question Three $\quad 46$

Question Four $\quad 46$

Question Five $\quad 51$

Question Six $\quad 52$

Question Seven $\quad 52$ 
CHAPTER 5. DISCUSSION, IMPLICATIONS AND RECOMMENDATIONS

Discussion

Question One

54

Question Two

56

Question Three

58

Question Four

59

Question Five

61

Question Six

62

Question Seven

63

Professional Implications and Recommendations 63

$\begin{array}{ll}\text { REFERENCES } & 67\end{array}$

APPENDICES 73

$\begin{array}{ll}\text { A. Questionnaire } & 73 \\ \text { B. Consent/Cover Letter for Participants } & 81 \\ \text { C. Follow-Up Letter } & 83\end{array}$ 


\section{LIST OF TABLES}

TABLE I: Size of Level II Fieldwork Facility 35

TABLE 2: Present Position of Respondents 35

TABLE 3: Learning Experiences Required of Level II

TABLE 4: $\begin{aligned} & \text { Quantity of Case Study Assignments Required } \\ & \text { of Fieldwork Students }\end{aligned}$

TABLE 5: Quantity of Treatment Plans Required of Fieldwork Students 40

$\begin{array}{ll}\text { TABLE 6: } & \text { Quantity of Standardized Evaluations } \\ \text { Required of Fieldwork Students } & 42\end{array}$

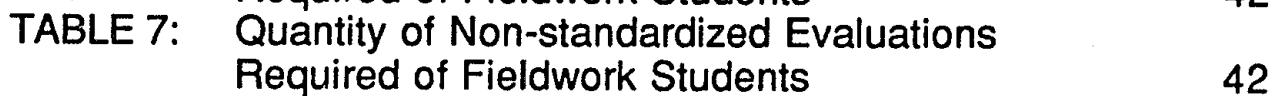

TABLE 8: Quantity of Patient Rounds Attendance Required of Fieldwork Students 43

TABLE 9: Quantity of Staff Conferences Required of Fieldwork Students 43

TABLE 10: Quantity of Reading Assignments Required of Fieldwork Students

TABLE 11: Quantity of Lecture Attendance Required of Fieldwork Students

TABLE 12: Student Involvement in Assignment Selection Based on Student Needs

TABLE 13: Student Involvement in Assignment Selection Based on Student Learning Styles 47

TABLE 14: Purpose of Didactic Assignments Required of Level II Fieldwork Students

TABLE 15: Type of Homework Required of Level II Fieldwork Students

TABLE 16: Time Students Spend Outside Work Hours to Complete Assignments 


\section{CHAPTER 1}

\section{INTRODUCTION}

\section{Purpose}

The purpose of this study was to explore one aspect of occupational therapy Level II Fieldwork, student didactic assignments, or learning activities. The purpose was twofold: 1) to determine current practices at fieldwork centers regarding quantity and type of assignments required of students, as well as expectations for student time use to complete assignments, and 2) to determine whether the required assignments are relevant to the educational goals of the fieldwork experience.

\section{Statement of the Problem}

Fieldwork education plays an integral role in the occupational therapist's educational process. During the required six months of fieldwork experience, the transition from student to professional takes place. One study has shown that the particular experiences of students during fieldwork can have a strong impact on future professional choices (Christie, Joyce, \& Moeller, 1985a).

"The process and content of fieldwork experiences have been debated over the years, yet the value of having an opportunity to apply theory to practice has never been denied" (Cohn, 1988, p. 9). Applying theory to 
practice, or integrating academic knowledge at progressively higher levels of performance and responsibility, is the purpose of fieldwork (American Occupational Therapy Association [AOTA], 1983). General guidelines are written to assist fieldwork educators in achieving this goal with students, but individual fieldwork centers may interpret these guidelines in a variety of ways.

Each fieldwork center possesses unique characteristics and philosophy of practice. Fieldwork educators are required to establish educational objectives in collaboration with academic faculty to reflect realistic learning outcomes given the types of learning experiences available at the individual setting (AOTA, 1983). Though the concept of clinic-school collaboration is ideal, in practice there may be decreased communication between schools and clinics (Cohn \& Frum, 1988), and individual supervisors are then responsible for developing specific objectives, content and format for fieldwork (Christie, Joyce, \& Moeller, 1985b). The student evaluation provided by the American Occupational Therapy Association lists objectives in the areas of student performance, attitude, and judgement (AOTA, 1987). These items may help fieldwork educators formulate the specific learning activities unique to the fieldwork setting (Crist \& Cooper, 1988).

Didactic assignments such as treatment plans, case studies, or special projects may be included as part of fieldwork objectives, as shown in a guide for writing fieldwork objectives provided by the AOTA (1980). These may be the learning experiences devised to assist siudents in acquiring the competencies of practice. Though the literature has addressed other aspects of fieldwork, it has not provided information on the content and meaning of didactic assignments in Level II Fieldwork. 
It has been shown that some fieldwork supervisors have little knowledge of adult learning (Cohn \& Frum, 1988) or of the process of teaching adults, including the individualization of teaching (Kautzmann, 1990). In addition to this, supervisors have identified needs for support and development of supervisory and teaching skills (Christie et al., 1985b). The needs of fieldwork educators, and the lack of literature on didactic assignments during occupational therapy fieldwork leads to many questions concerning the process and content of fieldwork education.

\section{Objectives}

The objectives of this study were to determine:

1. The types of didactic assignments currently being required of occupational therapy students during Level II Fieldwork by fieldwork centers.

2. The quantity of each type of didactic assignment required of Level II Fieldwork students.

3. Whether fieldwork centers allow variation in the assignments to reflect consideration of individual learning styles and needs of students.

4. The purpose of didactic assignments during Level II Fieldwork.

5. How didactic assignments are relevant to the educational goals of Level II Fieldwork.

6. The type of work expected outside of the fieldwork setting during the student's individual time.

7. How much time fieldwork supervisors estimate students spend to complete didactic assignments outside fieldwork time. 


\section{Questions}

This study was designed to answer the following questions:

1. What iypes of didactic assignments are required of Level II Fieldwork students by fieldwork centers in occupational therapy?

2. What is the quantity of each of the assignments required of Level II Fieldwork students?

3. Is each student at a particular center required to complete the same assignments, or is there variation reflecting consideration by fieldwork supervisors of the individual needs and learning styles of students?

4. What is the purpose of the didactic assignments required of Level II Fieldwork students?

5. How are didactic assignments relevant to the stated goals of fieldwork education?

6. What are the expectations of students for completing work outside the fieldwork setting?

7. How much time do fieldwork supervisors estimate students spend outside of fieldwork time on didactic assignments? 


\section{Definitions}

Didactic assignment: Tasks or activities used for the experience of teaching and learning. For the purpose of this study, these include:

1) written assignments: case study, treatment plan, patient evaluation, progress report, research paper, student notebook.

2) oral assignments: case presentation, research report.

3) other projects: field trip, administrative project, supervision of other student or volunteer, adaptive device construction.

Educational goals: Objectives listing expected competencies to be attained after a program of training and study.

Fieldwork education: The clinical internship phase of the occupational therapy education program.

Fieldwork setting/center: Hospitals, clinics, rehabilitation facilities, schools, or other agencies providing occupational therapy services and direct patient care, accepting Level II Fieldwork students.

Fieldwork supenvisor: A registered occupational therapist with at least one year of clinical experience acting as coordinator and manager to direct fieldwork education for students. This person may be involved in teaching activities with students, and may collaborate with occupational therapy schools. Other terms include fieldwork educator, clinical educator, and student supervisor.

Fieldwork time: The daily work hours a student is required to be at the fieldwork setting, engaging in fieldwork activities. 
Individual time: For this study, defined as a student's time outside of the fieldwork setting.

Level II Fieldwork: An in depth clinical internship providing students opportunities for the delivery of occupational therapy services to clients under the direct supervision of a registered occupational therapist, lasting at least six months.

Level $1 /$ Fieldwork student: An occupational therapy student engaging in Level II Fieldwork. Also referred to as intern or affiliate.

\section{Assumptions}

The assumptions for this study were:

1. That variation exists of current practices regarding the use of didactic assignments between settings and between fieldwork supervisors.

2. That fieldwork supervisors at each setting have stated objectives for fieldwork education.

3. That didactic assignments or learning tasks are required of fieldwork students and are included in the objectives.

4. That responses would be accurate, and representative of the general experiences required by fieldwork supervisors at one setting, although the information was provided by one occupational therapist. 


\section{Limitations}

The sample used was one of convenience, limited to fieldwork settings used by San Jose State University. The size is small relative to the total number of fieldwork settings and the sample is biased geographically with centers located in California. These limitations prevent generalization of the results to a larger and more diverse population.

The research method also contained limitations. Responses may have been biased, as only those therapists who were accessible and cooperative were included as participants. With a written survey questionnaire, there is always a chance that one will misinterpret a question, or not accurately answer a question. There was also a limited amount of qualitative information gathered to explain some of the responses.

The last set of limitations relates to the interpretation of the results. Independent variables were not controlled, and descriptive statistics alone were used. Causality cannot be determined.

\section{Significance of the Study}

This study obtained information on the current uses of didactic assignments required of occupational therapy students during Level II Fieldwork. It also attempted to clarify the purpose of these assignments. Fieldwork, the part of occupational therapy education which emphasizes the acquisition of clinical performance skills and competence as a therapist, is a critical part of a student's professional education. In response to demands for 
accountability and clarification, such aspects of fieldwork including student evaluation, supervisor preparation, protocols, and procedures related to fieldwork are constantly being re-evaluated and revised, necessary to maintain the quality and significance of fieldwork education. As stated in the Guide to Fieldwork Education (AOTA, 1988), "well organized and coordinated fieldwork education programs are expected to benefit not only the profession, but the student, the academic institution, and the fieldwork education center" (p. 2). As student assignments are part of the fieldwork education process, it was thought to be a benefit to examine them.

The American Occupational Therapy Association has stated that fieldwork shall be conducted in settings approved as providing experiences appropriate to the learning needs of the student and as meeting the objectives of fieldwork (AOTA, 1983). How one knows which experiences are effective, appropriate, and meaningful is not clear. Studies have shown that fieldwork supervisors, who often plan student learning experiences and objectives, have little knowledge of teaching adults (Cohn \& Frum, 1988) and that they need to develop skills for teaching and supervising (Christie et al., 1985b). There is a lack of expertise and consistency among fieldwork supervisors. These studies and others (Emery, 1984; Kautzmann, 1990; Pascoe, 1987; Scully \& Shepard, 1983; Windom, 1982) indicate that the process and content of fieldwork supervision needs refinement, development, and continued study.

The literature is limited regarding the actual didactic component of fieldwork education, or the extent of the use of didactic assignments. Students encounter a wide range and variety of experiences in fieldwork settings, but specific learning assignments are not well documented. Having information on 
the current practices may help fieldwork educators by providing an overview of possibilities, assisting in the planning of specific learning objectives, and stimulating thought into the purpose and meaning of such tasks. The information may also be helpful to academic faculty by providing a stimulus for communication and providing information to assist in preparing students for fieldwork. Lastly, this information may assist students in preparation, clarification of expectations, and as a basis to provide feedback to educators regarding their needs.

To ease the transition from student to professional therapist, students would benefit from being placed in a setting where they can experience learning activities which best facilitate their individual learning. Some didactic assignments may be viewed as a needless repetition of what was completed in school, others as a meaningful method to apply theory to actual clinical situations. This study may begin to answer such questions, by providing information on current practices and expectations held by fieldwork educators. 


\section{CHAPTER 2}

\section{LITERATURE REVIEW}

\section{Overview}

The literature review will provide background information relevant to fieldwork education in occupational therapy. The historical progression and development of fieldwork experience in occupational therapy education will first be presented, including standards and guidelines. The purpose and scope of Level II Fieldwork will then be presented, followed by student learning as well as clinical teaching and supervision to include studies of these subjects relevant to occupational therapy. Lastly, the frame of reference used for this study, the Occupational Performance model, will be discussed.

\section{History of Occupational Therapy Fieldwork Education}

The educational requirements for the registered occupational therapist have changed in content, scope, and length over time, but the two basic components of quality academic coursework and concurrent and subsequent clinical experience have continued since the first occupational therapy educational programs were developed. The role of fieldwork experience in occupational therapy education has been a critical part of the professional's development. 
The first professional school for occupational therapy was established by Eleanor Clarke Slagle in 1915 and was called the Henry B. Flavill School of Occupations (Dunton, 1921; Kidner, 1928; Loomis, 1992). This training course included two parts, one theoretical with technical training and the other practical work in hospitals or state institutions. Shortly after this time, there was an expansion of occupational therapy programs, some of which were war emergency courses. At that time the profession expanded as wounded men from World War I grew in number and a supply of trained occupational therapists was needed for the war hospitals. Occupational therapy was one of two classes of reconstruction aides; the other was physiotherapy. By 1918 many training courses were in operation (Kidner, 1928), which included a variety of courses with fieldwork practice in local hospitals a vital component (Hopkins, 1988).

The American Occupational Therapy Association (AOTA) established "Minimum Standards for Courses of Training in Occupational Therapy" in 1923 (Hopkins, 1988; Kidner, 1928). These were the first academic guidelines for occupational therapy educational programs. Programs were designed for a minimum of 12 months, with not less than 8 months of theoretical work and not less than 3 months of hospital practice training, under supervision (Kidner, 1928). These were minimum standards with coursework varying from 8 months to 4 years, and clinical training from 3 to 9 months.

A standing committee on education had been formed in 1922 to establish uniform standards for training and advancement of occupational therapists. In 1927 the committee studied practice training to determine the expectations of students by the hospital and the educational opportunities to 
be provided by the hospital (AOTA, 1928). This study was conducted using information provided by the committee members representing six occupational therapy schools and various practice centers. The participants provided mixed opinions but a general feeling that students needed more preparation in practical application and treatment prior to beginning clinical training. In 1927, at the annual meeting of the American Occupational Therapy Association, the required time in hospital practice training was increased from 3 to 6 months following a unanimous decision (Kidner, 1928).

In 1931, the AOTA requested that the American Medical Association inspect and approve occupational therapy schools. One of the outcome recommendations by the AOTA (1935) concerning fieldwork was that "A well defined program of lectures, clinics and staff meetings shall be offered by the hospital to each group of students" (p. 422) and that written records, case studies, and examinations shall be required of each student. Following this inspection and subsequent meetings, the "Essentials of an Acceptable School of Occupational Therapy" was established and adopted in 1935. The standard then included a course of 25 calendar months of full time training, which included 9 months of hospital practice training (AOTA, 1939). The 9 months in hospitals was specified as to length of time and diagnoses to be included. These essentials set the standards by which occupational therapy programs were to be accredited.

The early 1940's brought a period of growth as World War II again increased the need for therapists as the number of soldiers in war hospitals increased. In 1941 the committee on education was divided, and the first committee on clinical training was organized to help establish fieldwork 
guidelines (Ackley, 1960). Before that time, there was no standardization in any aspect of fieldwork. Each school developed individual schedules, grading policies, and patterns of operation, which overwhelmed the clinical centers by the variety and number of different policies. Schools were also submitting many inquiries and requests for information.

An article published in 1942 by Kahmann provided information and clarified standards for the schools in response to requests. During clinical training, the required time to be spent in patient contact was between $1 / 3$ and $2 / 3$ of the total hours, with the remaining time to be spent on theory, department organization, and activity preparation. The paper also stated that "Supervision of treatment measures, interpretation of methods and procedures, as well as requirement of written materials, sources of reference and reading matter, with opportunity for attending lectures and clinical demonstrations, are all essential requisites of good training" (Kahmann, 1942, p. 217).

The first effort of the committee on clinical training was uniformity in the scheduling of fieldwork, which took up to 5 years to become implemented (Ackley, 1960). The emphasis of the committee then shifted to the development of a student data sheet and grading report. The committee was renamed and became a subcommittee of the Commission on Education. The Commission and its committees continue to explore areas related to occupational therapy education.

Efforts were made in 1950 by the subcommittee of clinical training to update the student report. Fewer areas were selected to assess, but more descriptive, clearly delineated behavioral phrases were used in specifying the level and quality of performance expected. In 1953, a study was undertaken to 
determine existing standards and practices of occupational therapy in order to evaluate clinical practice programs. This study was conducted to review the quality of practice so that high quality student training could be ensured (Spackman, 1953).

Emphasis on accountability to consumers led to the development of new standards for education and practice. In 1970, the document "Standards and Guidelines for an Occupational Therapy Affiliation Program" was established. The educational objectives were written to reflect the philosophy and aims of student clinical education and were expected to be clearly defined for the student. The "Essentials of an Accredited Educational Program for the Occupational Therapist" in 1973 became the fourth revision of the first such document. In the new document, the requirement for fieldwork was changed from 9 to 6 months. It also provided guidelines for the evaluation of students including methods such as examination (written, oral, or practical), project papers, and demonstration.

Guidelines, essentials, and requirements for occupational therapy education, both academic and clinical, continue to be revised. Compared to earlier guidelines which specified type and length of clinical affiliation, broader statements permitting flexibility and varied experience with respect to type of patients, setting, and treatment have been used (Presseller, 1983). The most recent revision of the Essentials, the seventh revision, was approved in 1991. 


\section{Purpose of Fieldwork}

Successful completion of occupational therapy Level II Fieldwork is one of the educational requirements to assure adequate professional preparation. It helps to insure that the practitioner has the knowledge and skills for entry level practice. Level II Fieldwork is a period of sustained or full-time experience which is completed following the relevant academic coursework, and extends for a minimum period of six months (AOTA, 1991).

Supervised fieldwork experience in occupational therapy is intended to complement academic coursework by offering opportunities to apply knowledge, and to develop clinical skills and professional characteristics. At the completion of Level II Fieldwork, the student is expected to function at minimum entry level competence, and fieldwork experiences should provide opportunities to develop this competence (AOTA, 1988). The document "EntryLevel Role Delineation for OTRs and COTAs" serves as a guide to define minimum competencies of the entry level registered occupational therapist (AOTA, 1981).

As stated in the AOTA's Guide to Fieldwork Education, the purpose of occupational therapy fieldwork is to "provide occupational therapy students with the opportunity to integrate academic knowledge with application skills at progressively higher levels of performance and responsibility" (AOTA, 1988, p. 1). The AOTA's "Essentials and Guidelines of an Accredited Educational Program for the Occupational Therapist" state that Level II Fieldwork shall promote clinical reasoning and reflective practice, professionalism and ethics, 
as well as help to develop a repertoire of assessments and treatment interventions (AOTA, 1991).

In agreement with the above statements, Cohn (1989) described acquiring technical skills and developing clinical reasoning as two goals of fieldwork. Leonardelli and Gratz (1986) and Colman (1990) pointed out that these two aspects of professional education have been debated, and that there is a conflict between professional and technical goals, or theory and practice, in occupational therapy education. Some authors (Barrows, 1986; Cohn, 1989; Fidler, 1966; Parham, 1987) have argued that the development of problem solving skills, inquiry skills, creative thinking, and self-reflection should be the primary goals of fieldwork education in order to develop professional therapists who reflect on and incorporate theory into their practice and think beyond technical solutions to clinical problems. Fidler (1966) has argued that in order to become true professionals, the aim of education should be to foster creative thinking, and that activities and skills can be learned on the job and applied in relation to principles.

Though professional clinical reasoning may be the ultimate goal, developmental theorists report that one needs to learn routines and standards before developing creative alternatives (Cohn, 1989). This may lead to differing needs among students who want to learn skills but have difficulty with theory and integration.

In order to define the purpose and scope of any fieldwork education experience, the desired goals and end product need to be established. These are the expected minimum competencies (Barrows, 1986; Leonardelli \& Gratz, 1986). General objectives and competencies for fieldwork education have 
been identified by clinicians and academicians in occupational therapy, but each fieldwork center has individual characteristics and each facility's philosophy, organization, and environment directly affects the fieldwork education program (AOTA, 1988). This affects the experience and outcome for fieldwork students, as each center must establish educational objectives given the types of learning experiences available.

Patel and Cranton (1983) studied medical education using both ethnographic and experimental designs to look at transfer of student learning among cognitive, psychomotor, and affective domains among three clinical disciplines. Qualitative observational data was used to determine types of student learning, and tests were used to gain more objective data of student knowledge, problem solving, interpersonal and technical skill. The results indicated that different settings yielded different opportunities for learning and types of learning. The authors discussed the finding that the educational process in the clinical setting is much more affected by the environment than that in the classroom.

The AOTA Commission on Education has attempted to write national uniform fieldwork objectives for fieldwork centers, but it was soon decided that this was both overwhelming and unrealistic. Further, it would impose unnecessary constraints on individual fieldwork centers and inhibit flexibility (AOTA, 1980). Instead, a guide was written to aid supervisors in writing objectives, indicating that the objectives should be consistent with the entry level role delineation and fieldwork performance report.

Fieldwork objectives, or behavioral objectives, serve several purposes. They define the expected performance of the student and may promote self- 
directed learning. They provide a planning guide of learning experiences for the fieldwork educator as well as assistance with the evaluation of student performance. Learning experiences, or enabling activities, include specific opportunities which students will have available to develop and demonstrate abilities required by written objectives (AOTA, 1980). The AOTA recommends including objectives for both direct (screening, evaluation, program planning and implementing) and indirect (consultation, research) services.

The guide also provides examples of enabling activities which, for direct occupational therapy service, include observations and reports of a screening interview, records of observations of a specific performance skill, construction of an assistive device, assessment of a student-patient session, and written progress notes. Some examples for indirect service include conducting case study research projects, writing an occupational therapy policy, and surveying outside resources or therapists.

The Guide te Fieldwork Education (AOTA, 1988) suggests the use of a student manual created by the training facility that includes learning activities and objectives, as well as information on student responsibilities for treatment, records and work space, and estimated hours to be spent in various areas such as patient contact, preparation, records, instruction, and meetings.

\section{Student Learning}

Some studies have been conducted that relate to student learning styles in occupational therapy. Llorens and Adams (1978) used the Canfield-Lafferty Learning Styles Inventory to identify learning styles of undergraduate and 
graduate level occupational therapy students. They found that occupational therapy students prefer to learn by working with people and with direct experience. Students prefer learning conditions which permit: 1) personally knowing and liking the instructor; 2) setting their own objectives using feedback to modify goals; and 3) working independently and determining their own study plan.

Rogers and Hill (1980) conducted a similar study using the Rezler Learning Preferences Inventory. The authors found that occupational therapy students preferred learning experiences which were: 1) teacher structured, which are well organized with clear expectations and goals; 2) concrete, which relates to specific practical tasks and skills; and 3) interpersonal, which includes working directly with faculty members and students. A later study, using the same inventory and similar population yielded these same three preferences (Barris, Kielhofner, \& Bauer, 1985).

These studies were conducted in an attempt to understand learning styles of occupational therapy students, and clarify which types of experiences students prefer. This is important to examine as student performance and success during fieldwork may relate to the match between individual learning and the type of experiences, structure, and supervisory style presented to them. Students appear to prefer interpersonal experiences and clear objectives, with some degree of interaction and input with the instructor. It is important to recognize that learning styles are individual and vary.

As stated earlier, purposes of fieldwork are to facilitate learning practical treatment skills and theoretical clinical thinking. Developmental theorists agree that a person needs to learn routines and standards before developing 
creative alternatives (Cohn, 1989). The sequence of learning is from simple to complex, and practice of newly acquired skills is important for learning success (McPherson, 1976). Students may need to learn a repertoire of skills before they can begin to develop analytical ability and clinical reasoning. The literature also has indicated that $86 \%$ of occupational therapists have a bachelor's degree as their highest educational degree and students with a bachelor's degree have a lack of committment to theory (Parham, 1987). This may present a challenge to fieldwork educators and to students in their quest to integrate skills with abstract theory. According to Parham's findings, some students and supervisors may be more concerned with "hands on" or practical skills than with developing theoretical application and integration during fieldwork.

Student motivation has been found to be higher when the importance and relevance of subject content and prescribed learning are clear and when learners perceive themselves as being in control of the learning situation. Choice of instructional activities and self-pacing are part of student control (McPherson, 1976).

\section{Clinical Teaching and Supervision}

Supervision and clinical teaching of Level II Fieldwork students may be the responsibility of one supervising therapist, or may be shared among more than one therapist. An important consideration regarding clinical education is that most clinical supervisors or instructors are trained and educated primarily for patient care, not for education and teaching (Irby, 1978) and are frequently 
not prepared for the role of instructor/supervisor (Agriesti-Johnson, 1978). Also, there are requirements and responsibilities unique to clinical teaching, when compared to other educational environments. In addition to teaching, the clinical instructor must also supervise, demonstrate clinical competence, and model professional standards and values.

There is a lack of research on educational methods in occupational therapy and limited discussion of the effectiveness of methods being used (Gill, Marmo, \& Shuster, 1978; Leonardelli \& Gratz, 1986). This was found in the review of the literature for this study, including limited research or discussion of the fieldwork educational process and clinical teaching. The literature does, however, contain studies and articles related to fieldwork supervision in both occupational therapy and related health care fields (Christie et al., 1985b; Cohn, 1989; Emery, 1984; Kautzmann, 1990; Schwartz, 1984; Windom, 1982)

Clinical supervision, as stated above, has been explored by several studies. Christie et al. (1985b) obtained data through survey methodology from therapists and students in 65 fieldwork centers nationwide and described characteristics of effective and ineffective supervisors, as well as needs of occupational therapy supervisors. They found a lack of adequate preparation of supervisors, with $21 \%$ of supervising therapists lacking the required 1 year minimum of clinical experience and $32 \%$ feeling unprepared to supervise students. The American Occupational Therapy Association and academic programs develop guidelines for planning fieldwork, but objectives, content, and format are determined by individual supervisors. Supervising therapists have expressed a need for supervisory and teaching skill development. 
Supervisors' lists of problems from the above study included a lack of supervisory problem solving skills including evaluation and observation skills. The author also commented on the developmental sequence of supervisors. New supervisors begin with a rigid, self-centered style, and later become more flexible as they gain experience. They begin to accept the fact that they are not solely responsible for a student's performance (Christie et al., 1985b).

Scully and Shepard (1983) conducted an ethnographic study in physical therapy to examine the process of clinical education. They identified two major components contributing to the process: 1) the clinical teaching situation, and 2) teaching tools used by clinical teachers. The teaching situation included organizational factors and ground rules set by the academic setting, the hospital, and the physical therapy department within the hospital. One of the factors is patient primacy, meaning that the quality of patient care is the primary goal for all concerned, and education is secondary.

Also explored were clinical trainer and student factors. The clinical trainer's role is to assess, guide, and promote the student, to pace the student, and enable a shift from the role of observer to the role of staff member. An important aspect for the student is the degree of professional maturity the student possesses. Students vary in capabilities, learning, and prior knowledge, but the end result is the same for all.

Because of environmental ground rules, patient primacy, and level of professional maturity, it was found that teaching tools were extremely flexible, but had two consistent properties. One property is to yield student learning with minimal risk to the patient, learner, teacher, hospital, and profession, and the other is to advance the student to clinical competency. The authors 
concluded that clinical teaching tools were charcteristically unlike most academic teaching tools. The teaching tools which were found to be used by clinical instructors include: 1) diagnosis of readiness of the student, which is achieved through verbal exchange, performance tests, and observation to establish a baseline from which to begin the clinical teaching process; 2) selection of clinical problems and knowledge oriented activities which provide varied and interesting learning material; 3) supervision, the main clinical teaching tool, which includes both supportive and instructive responsibilities through dynamic enabling activities; and 4) ongoing evaluation.

Kautzmann (1990) studied occupational therapy clinical teachers' attitudes and values related to fieldwork education using Knowles' principles of adult learning. The authors found that therapists ranked methods and activities related to individualization or supervisor-student collaboration lowest even though the principles were valued. This is usually a greater issue with new supervisors who tend to follow more rigid guidelines with less collaboration or flexibility for individual students.

Cohn (1989) pointed out that supervisors have little knowledge of adult teaching and with a minimum of one year experience, may also have limited clinical knowledge. Cohn also stated that supervision is difficult due to the discrepancy between theory and practice and the difficulty integrating the two.

A study by Emery (1984) of physical therapy students' perspectives of clinical teachers indicated that the factors identified as most important, communication and interpersonal skills, are not those targeted by instructor training programs. The author concluded that the inconsistency of education of clinical teachers may be due to the lack of understanding of what they need. 
Fidler (1966) has written on the process of education and advocates professional versus technical education. She described teaching as making opportunities available for developing a body of knowledge, skills, and attitudes to enhance the learner's capacity to function creatively with skill and understanding. She pointed out that learning complex didactic information requires structured approaches and therefore skilled planning, and that knowledge must be integrated and have personal value and significance in order for the student to retain it. Structured group process, role play, selfevaluative diaries or logs, and activity labs are all suggested for integrative learning.

Meyers (1989) conducted a naturalistic study using students and supervisors from three Level II Fieldwork settings to determine ideal and actual fieldwork environments. Meyers identified factors that contribute to an ideal environment including opportunity to integrate theory in practice and assignments or special projects related to patient care. Each setting reported a different priority of ideal factors, which the authors believe suggests there may be no ideal Level II Fieldwork environment for all practice areas.

Fieldwork educators use many methods of teaching in the clinical setting, based on their resourcefulness and available information (AgriestiJohnson, 1978). Ford (1978) discussed using a systems approach to student learning in clinical education for allied health professionals, which involves both the student and teacher. He believes it is important to focus on the individual to determine the most effective method of teaching. Knowing the student and the abilities that he/she brings to the program can help determine clear appropriate behavioral objectives (Ford, 1978). This method is also 
advocated in a handbook for health professionals on teaching techniques (Foley \& Smilansky, 1980). The authors suggest designing a sequence of instructional activities after determining knowledge, attitude, and skills of the student.

Learning experiences and teaching methods, though not well researched, have been discussed for clinical education by several authors. Case study has been widely used and promoted (Line, 1969; Neistadt, 1987; Pelland, 1987). Foley and Smilansky (1980) have suggested the use of simulations and role play, discussion and problem solving, computer aided instruction, written simulations, and case studies. McPherson (1976) includes the above as well as the use of video and audio tapes, study guide, reading material, research, and field trips. Scully and Perry (1977) state that learning experiences are not limited to patient care in the clinic and that administrative, research, and educational activities are appropriate student assignments during clinical education.

The American Occupational Therapy Association surveyed 50 fieldwork centers to obtain data on student affiliation (AOTA, 1963). One portion of the questionnaire used to investigate student assignments yielded data for 130 fieldwork students. Data for the 130 students revealed that case studies were required in 106 cases, and student notebooks which reported treatment plans, reference information, lecture notes, progress notes, and other assignments were required in 99 cases. Reference reading was required in 39 cases, special project in 22 , a written paper in 25 , and activity analysis in 4 cases. It was not discussed how many of the 50 fieldwork centers were represented by these numbers. Educational opportunities available to students included 
lectures, clinics, medical rounds, field trips, training in activities of daily living, and meetings. Students also commented on experiences that they thought were unnecessary and these were repetition of lectures, paperwork (case studies and reports), and excessive treatment plans and progress notes. Students wished for more patient treatment application and treatment techniques.

Directors of student affiliation centers were interviewed as another portion of the curriculum study, with a total of 48 respondents. They reported on student treatment related duties which included obtaining information, treatment planning, and completing written and verbal reports. The most common written requirement, progress notes, was required in 45 cases, and the most common verbal requirement, reporting in rounds, was required in 26 cases. One third of the centers required reading assignments.

\section{Frame of Reference}

Occupational performance is defined as one's ability to accomplish the tasks required by his or her role, related to his or her developmental stage (AOTA, 1974). There are subcomponents of occupational performance, which are called performance components, including motor, sensory-integrative, cognitive, psychological, and social. These elements contribute together to performance skills which are work, play/leisure, and self care activities (Pedretti \& Pasquinelli, 1990).

Learning through enabling and purposeful experiences is a primary process of the Occupational Performance model, necessary to establish a 
balance between the performance components and assist in skill performance. During fieldwork experience, the student must progress from the role of student to the role of therapist, and in the process, become competent and independent in the tasks required by this role. Just as the model can be applied to a treatment continuum (Pedretti \& Pasquinelli, 1990), it may be applied to the developmental learning process.

For example, one of the earlier stages of learning involves enabling activities, which may be non-purposeful practice activities to prepare for purposeful activities. These enabling activities may include a variety of learning tasks and assignments. The next stage, purposeful activities, includes more meaningful role related tasks and may include actual patient treatment as well as those tasks required to complete the scope of evaluation, planning, and treatment. Finally, the last stage is the resumption of occupational performance roles, or in this case the new role of therapist. Throughout the educational process learning occurs in each of the five performance components, which means that in addition to cognitive learning, motor, sensory-integrative, psychological, or social learning are important and require consideration by supervisors who plan a fieldwork educational experience.

\section{Summary}

Throughout the history of the profession, fieldwork experience and academic coursework have remained the two most vital components of occupational therapy professional education. The profession has chosen to continue its exploration and clarification of expectations, standards, and 
requirements of students, teachers, and clinical supervisors. The primary purpose of fieldwork education is to prepare competent clinicians. The method of education in individual settings has not been studied or well documented. Recommendations have been made for the type of experiences or learning opportunities available including, for example, written and reading assignments. The purpose of fieldwork, to develop clinical skills and professional characteristics, must be accomplished by a variety of students with different learning needs in a variety of different settings. The use of didactic assignments may be used for this purpose, but the type, frequency, and meaning have not been well documented. The optimal fieldwork situation would present a challenging and interesting experience to increase the student's involvement and commitment to expand his/her learning. Clinical supervisors often lack preparation and skills for this responsibility, but must find learning experiences to assist each student to progress to the same basic level of competence. 


\section{CHAPTER 3}

\section{DESIGN AND METHODOLOGY}

\section{Purpose and Objectives}

The main purpose of this study was twofold: 1) to determine current practices at fieldwork centers having an affiliation with San Jose State University regarding quantity and type of assignments required of students, as well as expectations for student time use to complete assignments, and 2) to determine whether the required assignments are relevant to the educational goals of the fieldwork experience.

The objectives of this study were to determine: the types of didactic assignments currently being required of occupational therapy students during Level II Fieldwork by fieldwork centers; the quantity of each type of didactic assignment required; whether fieldwork centers allow variation in the assignments to reflect consideration of individual learning styles and needs of students; the purpose of didactic assignments during Level II Fieldwork; the relevance of didactic assignments to the educational goals of the experience; and the type and amount of work expected of Level II Fieldwork students outside of the fieldwork setting during the student's individual time. 


\section{Questions}

This study was designed to answer the following questions:

1. What types of didactic assignments are required of Level II Fieldwork students by fieldwork centers in occupational therapy?

2. What is the quantity of each of the assignments required of Level II Fieldwork students?

3. Is each student at a particular center required to complete the same assignments, or is there variation reflecting consideration by fieldwork supervisors of the individual needs and learning styles of students?

4. What is the purpose of the didactic assignments required of Level II Fieldwork students?

5. How are didactic assignments relevant to the stated goals of fieldwork education?

6. What are the expectations of students for completing work outside the fieldwork setting?

7. How much time do fieldwork supervisors estimate students spend outside of fieldwork time on didactic assignments? 
Subjects

The subjects for this study comprised a sample of convenience. The sample was taken from the data base of Level II Fieldwork centers which have agreements with the San Jose State University Department of Occupational Therapy, and currently accept students. All fieldwork centers in California fitting this description were used, constituting a sample size of 159 fieldwork centers.

\section{Procedure}

This study was descriptive and non-experimental in design using survey methodology. The instrument used was a questionnaire (Appendix A) written by the researcher. Prior to mailing of questionnaires, a pilot survey was completed by two faculty members, and five occupational therapists who work in clinical settings where Level II Fieldwork students are accepted. The pilot survey was completed to obtain feedback for revision and clarification of the questions.

The questionnaire included 23 questions. The first 8 questions requested demographic information, while the remaining 15 questions related to learning experiences used for the education and training of Level II Fieldwork students at each setting. Most questions were closed-ended with space to add additional information provided for in three of the questions. Variables which were included as questions in the survey, but not controlled 
for were the type and size of facility, length of time supervising students, and years of experience by the therapist.

The questionnaire was mailed directly to the person whose name was on file at San Jose State University as the site contact person for fieldwork. The questionnaire was to be completed by a registered occupational therapist who was either the fieldwork coordinator, or occupational therapy supervisor at the site. If there was no such position, or this person was unable to complete the questionnaire, a staff occupational therapist who supervises students was expected to complete the survey.

The mailed questionnaire was to be completed at the respondent's convenience and was expected to have taken approximately 20 minutes to complete. The questionnaires were mailed, together with the cover/consent letter (Appendix B) and a stamped return envelope, on February 3, 1992. A follow-up letter (Appendix C) was mailed February 18, 1992 to all participants as a reminder to complete and return the questionnaire. The deadline for receipt of questionnaires was March 6, 1992.

\section{Data Analysis}

The data were analyzed using descriptive statistics, including frequency distribution, measures of central tendency (mean and medians) and standard deviation.

Variables which were examined to determine demographic information included: present position, highest academic degree obtained, years as a registered occupational therapist and as a fieldwork supervisor, person with 
primary responsibility for planning and supervising fieldwork students, size of facility, and practice area.

Variables examined in the body of the questionnaire included: the types and amount of learning experiences used, type and amount of student homework expected, whether assignments varied following consideration of students needs and learning styles, orientation of students to fieldwork objectives, importance of fieldwork goals, and purpose of assignments. 


\section{CHAPTER 4}

\section{DATA AND RESULTS}

One hundred and fifty nine questionnaires were mailed to Level II Fieldwork centers in California having an affiliation agreement with San Jose State University. One hundred and eighteen $(74.2 \%)$ were returned. Of this total, 112 were completed with valid, usable data. This constitutes a return of $70.4 \%$. Of the remaining 6,1 was returned undeliverable, 1 was incomplete and data were included for more than one setting, and 4 were returned because the settings did not have current or appropriate information to provide.

\section{Demographic Data}

The respondents to the survey questionnaire were occupational therapy fieldwork educators at Level II Fieldwork centers in California. Respondents were asked to check the major area of practice used for the purposes of Level II Fieldwork education. Psychosocial dysfunction was the major practice area in $43(38.4 \%)$ cases, physical disabilities was the major practice area in 58 $(51.8 \%)$ cases, and $11(9.8 \%)$ marked other. Of those with a response of other, the following were the written responses: adult day health (1), work hardening/hand therapy (1), pediatrics (4), and both psychosocial and physical dysfunction in combination (5).

Table 1 summarizes the size of the facilities offering Level II Fieldwork responding to this survey. This number represents the patient bed capacity or 
Table 1

Size of Level Il Fieldwork Facility ( $n=104)$

\begin{tabular}{lrr}
\hline Number of Patients/Beds & $\underline{\mathbf{n}}$ & Percent \\
\hline $0-50$ & 34 & 32.7 \\
$51-100$ & 20 & 19.2 \\
$101-200$ & 16 & 15.4 \\
$201-500$ & 23 & 22.1 \\
$501-1000$ & 9 & 8.7 \\
$>1000$ & 2 & 1.9 \\
\hline
\end{tabular}

Note: Missing responses $=8$

Table 2

Present Position of Respondents $(N=112)$

\begin{tabular}{lcr}
\hline Position & n & Percent \\
\hline Manager & 24 & 21.4 \\
Supervisor & 30 & 26.8 \\
Senior Therapist & 32 & 28.6 \\
Staff Therapist & 11 & 9.8 \\
Other & 15 & 13.4 \\
\hline
\end{tabular}


caseload for the facility. The mean size was 186 patients/beds, with a standard deviation of 209.73. There was a range from 8 to 2000 .

The present positions of the occupational therapists completing the questionnaire are summarized in Table 2. Of the 112 responses, the following were the positions: 24 managers, 30 supervisors, 32 senior therapists, 11 staff therapists, and 15 with a response of other. Of the other responses, 9 were in an education related position such as occupational therapy instructor/educator, or clinical coordinator/specialist, and 5 were managerial positions including chief of occupational therapy, executive director, and assistant administrator. The remaining response was OTR III.

The current educational status of the respondents was obtained by asking the highest degree obtained. The following were the 112 responses: $83(74.1 \%)$ with a Bachelor's degree; $27(24.1 \%)$ with a Master's degree; 1 (.9\%) with a Doctorate; and $1(.9 \%)$ marking other, with a special COTA to OTR degree.

The amount of experience of the respondents was determined by asking the number of years as a Registered Occupational Therapist (OTR), and the number of years as a fieldwork supervisor. The number of years as an OTR ranged from less than one year to 42 years, with a mean of 13.6 (standard deviation 8.53), and median of 11.0. The number of years as a fieldwork supervisor ranged from less than one year to 38 years, with a mean of 7.5 (standard deviation 6.37) and median of 5.5.

There were two additional questions in the demographic section relating to which position had responsibility for planning and supervising Level II Fieldwork, both of which yielded 112 responses. The results for the person 
with primary responsibility for planning Level II Fieldwork are as follows: Occupational Therapy Manager/Director, 39 (34.8\%); Fieldwork Supervisor, 23 (20.5\%); Fieldwork Coordinator, 34 (30.4\%); Staff Occupational Therapist, 8 (7.1\%); and other, 8. The responses for other included senior occupational therapist $(n=3)$, occupational therapy instructor $(n=2)$, and assistant manager/chief $(n=3)$. The results for the person with primary responsibility for supervising Level II Fieldwork students are: Occupational Therapy Manager/Director, 12 (10.7\%); Fieldwork Supervisor, 22 (19.6\%); Fieldwork Coordinator, 11 (9.8\%); Staff Occupational Therapist, 64 (57.1\%); and other, 3. The responses to other included senior occupational therapist $(n=2)$ and OTR III $(n=1)$.

\section{Research Questions}

The data and results for the seven research questions will follow each stated question.

Question 1: What types of didactic assignments are required of Level II Fieldwork students by fieldwork centers in occupational therapy?

Respondents were asked to check from a list of assignments, or learning experiences, those which they require of Level II Fieldwork students at their facility. There was space to include any additional assignments which were required. Forty-four (39.3\%) respondents stated assignments in addition to those listed. This $n(44)$ is the number of respondents of the total who included additional assignments, but does not reflect whether more than one assignment was listed. Of those including other assignments, respondents 
listed from 1 to 3 additional assignments. Assignments required by respondents, including those from the assignment list as well as those additionally noted by respondents are listed in Table 3.

Question 2: What is the quantity of each of the assignments required of Level II Fieldwork students?

The list of assignments from the questionnaire was the same as for question number 1 above. Respondents were asked to fill in the number of assignments required of a Level II Fieldwork student during one 3 month fieldwork period. Data are presented in text and/or in tables depending on which is most clear. Those responding with a checkmark but no numbers were not included and were counted as missing for the purposes of this question.

Table 4 includes data from respondents requiring case study assignments $(n=84)$. Responses ranged from 1 to 8 case studies required, with a mean of 1.4. Table 5 summarizes data from respondents requiring treatment plans $(n=92)$. Those responses including weekly, 2 or 3 times a week, or daily, were converted to numbers, $12,24,36$, and 60 respectively, based on the 12 week internship. The number of required treatment plans ranged from 1 to 60 , with a mean of 10.2 .

For the progress note assignment, there was considerable variability including responses such as "daily for each patient seen," "varies," or "weekly on all patients" rather than specifying numbers. The number of responses was 97 , with 15 missing responses. The range in number of progress notes required was 1 to 75 . Of the 97 responses, 51 (52.6\%) required daily progress notes (with the possibility of greater than 1 patient note per day). The next most frequent response was stated by $7(7.2 \%)$ respondents requiring 
Table 3

Learning Experiences Required of Level 1 Fieldwork Students $(N=112)$

\begin{tabular}{lrr}
\hline Learning Experiences & $n$ & Percent \\
\hline Progress Note & 112 & 100.0 \\
Treatment Plan & 108 & 96.4 \\
Oral Presentation & 103 & 92.0 \\
Staff Conference & 99 & 88.4 \\
Standardized Evaluation & 96 & 85.7 \\
Field Trip & 95 & 84.8 \\
Case Study & 92 & 82.1 \\
Other Evaluation & 85 & 75.9 \\
Reading Assignment & 80 & 71.4 \\
Patient Rounds & 74 & 66.1 \\
Lecture Attendance & 70 & 62.5 \\
Adaptive Equipment/Splint Construction & 64 & 57.1 \\
AdministrativeProject & 37 & 33.0 \\
Student Notebook & 35 & 31.3 \\
Journal & 33 & 29.5 \\
Supervision Experience & 32 & 28.6 \\
Research Paper & 29 & 25.9 \\
Video & 8 & 7.1
\end{tabular}

Additional Learning Experiences Noted by Respondents:

Project

Activity/Group Protocol

17

Activity Analysis

Interdisciplinary Interview

11

8

Family Training/Conference

6

Inservice

Other Paper

Training Programs

Compare/Implement Theory in Treatment

Drug Reference Cards

Community Resource Book

Initial Impressions Report

Conference Progress Reports

Videoflouroscopic Study

Journal Report

Serial Casting

Equipment Demonstration

Intakes

Attend Professional Meeting

Picture Analysis of Body

Quality Assurance

15.2

9.8

7.1

5.4

2.7

1.8

1.8

1.8

Home Visits 
Table 4

Quantity of Case Study Assignments Required of Fieldwork Students $(n=84)$

\begin{tabular}{lrr}
\hline Required Number of Case Studies & n & Percent \\
\hline 1 & 66 & 78.6 \\
2 & 13 & 15.5 \\
$3-5$ & 3 & 3.6 \\
$6-8$ & 2 & 2.4
\end{tabular}

Note: Missing Responses $=28$.

Table 5

Quantity of Treatment Plans Required of Fieldwork Students ( $n=92$ )

\begin{tabular}{lrr}
\hline Required Number of Treatment Plans & n & Percent \\
\hline 1 & 21 & 22.8 \\
2 & 8 & 8.7 \\
$3-5$ & 15 & 16.3 \\
$6-10$ & 20 & 21.7 \\
$11-20$ (weekly) & 19 & 20.7 \\
$21-40$ (2-3x weekly) & 5 & 5.4 \\
$41-60$ (daily) & 4 & 4.3 \\
\hline
\end{tabular}

Note: Missing Responses $=20$. 
weekly progress notes.

Table 6 summarizes data of those fieldwork centers requiring standardized evaluations as assignments $(n=82)$. The range was from 1 to 60 required. Table 7 summarizes data of those requiring other evaluations as assignments ( $n=75$ ), again ranging from 1 to 60 required.

The number of respondents requiring adaptive equipment or splint construction was 58 , with 54 missing responses, ranging from 1 to 5 required constructions. Of the $58,26(44.8 \%)$ required only $1,19(32.8 \%)$ required 2 , and $13(22.4 \%)$ required $3-5$.

A student notebook was another of the assignments listed. Of the 112 total, 35 (31.3\%) respondents required this as an assignment, but none listed a number greater than 1. There were 77 missing responses. A journal was a similar assignment listed. Of the 33 respondents requiring this assignment, 19 (69.7\%) required 1 assignment, $3(9.1 \%)$ required $2-3$ assignments, 3 (9.1\%) required 12 weekly assignments, and $4(12.1 \%)$ required 60 daily assignments. There were 79 missing responses.

Of the 29 respondents who required research papers, 27 (93.1\%) required 1 paper, 1 (3.4\%) required 2 papers, and $1(3.4 \%)$ required 8 papers. There were 83 missing responses.

Of the 88 respondents requiring field trips, the range was from 1 to 5 required field trips. There were 24 missing responses. Of the 88 requiring field trips, $41(46.6 \%)$ required 1 field trip, $33(37.5 \%)$ required 2 field trips, 10 $(11.4 \%)$ required 3 field trips, $1(1.1 \%)$ required 4 field trips, and $3(3.4 \%)$ required 5 field trips.

Table 8 summarizes the data for those requiring patient rounds as a 
Table 6

Quantity of Standardized Evaluations Required of Fieldwork Students $(n=82)$

\begin{tabular}{lrc}
\hline Required Number of Standardized Evaluations & $n$ & Percent \\
\hline $1-2$ & 24 & 29.3 \\
$3-5$ & 23 & 28.0 \\
$6-10$ & 20 & 24.4 \\
$11-20$ & 9 & 11.0 \\
$>20$ & 6 & 7.3
\end{tabular}

Note: Missing Responses $=30$.

Table 7

Quantity of Non-standardized Evaluations Required of Fieldwork Students $(\mathrm{n}=75)$

\begin{tabular}{lrc}
\hline Required Number of Evaluations & D & Percent \\
\hline $1-2$ & 27 & 36.0 \\
$3-5$ & 20 & 26.7 \\
$6-10$ & 13 & 17.3 \\
$11-20$ & 9 & 12.0 \\
$>20$ & 6 & 8.0 \\
\hline
\end{tabular}

Note: Missing Responses $=37$. 
Table 8

Quantity of Patient Rounds Attendance Required of Fieldwork Students $(n=63)$

\begin{tabular}{lrr}
\hline Required Number of Patient Rounds & $\mathrm{n}$ & Percent \\
\hline $1-5$ & 7 & 11.1 \\
$6-10$ & 6 & 9.5 \\
$11-20$ (weekly) & 35 & 55.6 \\
$21-36$ (2-3x weekly) & 9 & 14.3 \\
60 (daily) & 6 & 9.5
\end{tabular}

Note: Missing Responses $=49$.

Table 9

Quantity of Staff Conferences Required of Fieldwork Students ( $n=85$ )

\begin{tabular}{lrr}
\hline Required Number of Staff Conferences & n & Percent \\
\hline $1-5$ & 15 & 17.6 \\
$6-10$ & 9 & 10.6 \\
$11-20$ (weekly) & 47 & 55.3 \\
$21-36$ (2-3x weekly) & 7 & 8.2 \\
60 (daily) & 7 & 8.2 \\
\hline
\end{tabular}

Note: Missing Responses $=27$. 
student assignment with a total $n=63$, and a range from 1 to 60 required. The most common response was 12 weekly with $32(50.8 \%)$ of the 63 listing this response. Staff conferences were required by 85 respondents and these data are summarized in Table 9. Again the most common response was 12 weekly with $42(49.4 \%)$ of the 85 listing this response.

Ninety-five respondents required oral presentations of Level II Fieldwork students. There were 17 missing responses. Of the 95 , there was a range from 1 to 12 required oral presentations. Fifty-three (55.8\%) required 1 oral presentation, $27(28.4 \%)$ required 2 oral presentations, $11(11.6 \%)$ required 35 oral presentations, and $4(4.2 \%)$ required $>6$ oral presentations.

Of the 35 respondents who required an administrative project, all required only one project. There were 77 missing responses. Of the 28 respondents requiring a supervisory assignment, $21(75.0 \%)$ required 1,4 $(14.3 \%)$ required 2 , and $3(10.7 \%)$ required $>3$. There were 84 missing responses. There were 7 respondents requiring a video assignment with 105 missing responses. Of the $7,5(71.4 \%)$ required 1 , and $2(28.6 \%)$ required $2-3$ video assignments.

Reading assignments were required by 73 respondents and data are summarized in Table 10. There was a range from 1 to 60 reading assignments required. The final assignment was lecture attendance and these data are summarized in Table 11. There were 61 respondents included in this table who required lecture attendance. 
Table 10

Quantity of Reading Assignments Required of Fieldwork Students $(n=73)$

\begin{tabular}{lrr}
\hline Required Number of Readings & $\underline{\mathrm{n}}$ & Percent \\
\hline 1 & 42 & 57.5 \\
2 & 8 & 11.0 \\
$3-5$ & 10 & 13.7 \\
$6-8$ & 7 & 9.6 \\
$9-15$ & 4 & 5.5 \\
$>15$ & 2 & 2.7
\end{tabular}

Note: Missing Responses $=39$.

Table 11

Quantity of Lecture Attendance Required of Fieldwork Students ( $n=61$ )

\begin{tabular}{lrr}
\hline Required Number of Lectures & $\underline{\mathrm{n}}$ & Percent \\
\hline 1 & 19 & 31.1 \\
$2-5$ & 20 & 32.8 \\
$6-10$ & 5 & 8.2 \\
$11-15$ & 11 & 18.0 \\
$16-24$ & 6 & 9.8
\end{tabular}

Note: Missing Responses $=51$. 
Question 3: Is each student at a particular fieldwork center required to complete the same assignments, or is there variation reflecting consideration by fieldwork supervisors of the individual needs and learning styles of students?

The fieldwork supervisors were asked whether they explore each student's learning preferences through information or discussion obtained from the student. One hundred and eight (96.4\%) said they consider each student's learning needs and preferences. Only $2(1.8 \%)$ responded no, and there were 2 questionnaires with missing responses. Those indicating that they vary the type and/or number of assignments based on student needs were $86(76.8 \%)$, with the remaining $26(23.2 \%)$ responding that they do not, for a total $N=112$. Of the 86 answering yes, 79 said that they involve the student to some extent in the selection of assignments. Table 12 summarizes the extent to which students are involved.

The respondents were also asked whether they vary the type and/or number of assignments based on student learning style. Seventy seven $(68.8 \%)$ responded yes, and $35(31.3 \%)$ responded no, for a total $N=112$. Of those responding yes, 72 involve the student to some extent based on learning style. Table 13 summarizes the extent to which students are involved.

Question 4: What is the purpose of the didactic assignments required of Level II Fieldwork students?

Respondents were given a choice of five possible purposes for each of the didactic assignments, and asked to indicate which they considered most appropriate. More than one purpose could be marked for each assignment. The possible choices included: research skills/data collection; problem 
Table 12

Student Involvement in Assignment Selection Based on Student Needs $(n=86)$

\begin{tabular}{lcc}
\hline Student Involvement & n & Percent \\
\hline $\begin{array}{l}\text { lnvolved/Collaborate on } \\
\text { Most Assignments }\end{array}$ & 23 & 26.7 \\
$\begin{array}{l}\text { Involved/Collaborate on } \\
\text { Several Assignments }\end{array}$ & 56 & 65.1 \\
$\begin{array}{l}\text { Not Involved } \\
\text { Supervisor Determines Choices }\end{array}$ & 7 & 8.1 \\
\hline
\end{tabular}

Table 13

Student Involvement in Assignment Selection Based on Student Learning Styles $(n=77)$

\begin{tabular}{lcc}
\hline Student Involvement & n & Percent \\
\hline $\begin{array}{l}\text { Involved/Collaborate on } \\
\text { Most Assignments }\end{array}$ & 22 & 28.6 \\
$\begin{array}{l}\text { Involved/Collaborate on } \\
\text { Several Assignments }\end{array}$ & 50 & 64.9 \\
$\begin{array}{l}\text { Not Involved } \\
\text { Supervisor Determines Choices }\end{array}$ & 5 & 6.5 \\
\hline
\end{tabular}


solving/integration; communication skills, oral and/or written; reinforce treatment techniques/"hands-on"; and supervisory or administrative skills.

For each assignment there were a number of missing responses where no purpose was checked. The following are those numbers of missing responses from each assignment on the list used for the questionnaire: case study, 7; treatment plan, 3; progress note, 4; standardized evaluation, 8; other evaluation, 23; adaptive equipment, 32; research paper, 43; field trip, 15; patient rounds, 22; staff conferences, 6; oral presentation, 6; administrative, 42; supervisory, 38; video, 73; reading, 10; and lecture, 15. Some of the missing responses were from those who did not require the assignment, but others who did not require the assignment did include purposes.

Table 14 lists the didactic assignments and the number of respondents choosing each purpose, with a possible total for each being 112. Percentages are not calculated here due to the variability in missing responses and therefore valid response data.

The following data refer to each purpose and list those assignments which respondents indicated were used for each purpose (based on the subset of respondents including some response). Only those assignments in which at least $50 \%$ of respondents chose that purpose will be listed.

For the purpose of developing research and data collection skills the following assignments were included: research paper, $89.9 \%$; case study, $73.3 \%$; reading, $72.5 \%$; standardized evaluation, $69.2 \%$; other evaluation, $60.7 \%$; and video presentation, $56.4 \%$.

For the purpose of problem solving and integration the following assignments were chosen: treatment plan, $94.5 \%$; equipment or splint 
Table 14

Purpose of Didactic Assignments Required of Level II Fieldwork Students

\begin{tabular}{|c|c|c|c|c|c|}
\hline Assignment & ${ }_{A}$ (for & $\begin{array}{c}r \text { each } \\
\text { B }\end{array}$ & $\begin{array}{c}\text { purpos } \\
\text { C }\end{array}$ & $\left.e^{*}\right)_{D}$ & $E$ \\
\hline Case Study & $77^{\star \star}$ & 75 & 73 & 43 & 6 \\
\hline Treatment Plan & 33 & 103 & 68 & 76 & 5 \\
\hline Progress Note & 29 & 61 & 99 & 56 & 5 \\
\hline Standardized Evaluation & 72 & 71 & 62 & 54 & 1 \\
\hline Other Evaluation & 54 & 62 & 47 & 52 & 2 \\
\hline Splint/Equipment Construction & 9 & 58 & 10 & 74 & 1 \\
\hline Research Paper & 62 & 35 & 41 & 27 & 9 \\
\hline Field Trip & 46 & 31 & 27 & 58 & 15 \\
\hline Patient Rounds & 28 & 50 & 80 & 42 & 13 \\
\hline Staff Conferences & 26 & 66 & 96 & 40 & 31 \\
\hline Oral Presentation & 40 & 49 & 104 & 28 & 19 \\
\hline Administrative Project & 30 & 32 & 29 & 14 & 58 \\
\hline Supervision Experience & 2 & 33 & 45 & 21 & 70 \\
\hline Video & 22 & 22 & 27 & 22 & 10 \\
\hline Reading & 74 & 52 & 27 & 67 & 7 \\
\hline Lecture & 45 & 45 & 22 & 74 & 10 \\
\hline
\end{tabular}

Note: " The following are the purposes from which respondents chose.

The assignment will serve to develop in the student the following skills or abilities:

$$
\begin{aligned}
& A=\text { Research Skills/ Data Collection } \\
& B=\text { Problem Solving/ Integration } \\
& C=\text { Communication Skills } \\
& D=\text { Treatment Technique/ Hands-On } \\
& E=\text { Supervisory or Administrative }
\end{aligned}
$$

** Respondents could mark more than one purpose for each assignment. Each $\mathrm{n}$ is from a possible 112. Please see text for numbers of missing responses for each assignment. 
construction, $72.5 \%$; case study, $71.4 \%$; evaluation, $69.7 \%$; standardized evaluation, $68.3 \%$; staff conferences, $62.3 \%$; progress note, $56.5 \%$; video presentation, 56.4\%; patient rounds, $55.5 \%$; reading, $51.0 \%$; and research paper, $50.7 \%$.

The purpose of developing communication skills was marked by respondents for the following assignments: oral presentation, $98.1 \%$; progress note, $91.7 \%$; staff conferences, $90.6 \%$; patient rounds, $88.9 \%$; case study, $69.5 \%$; video presentation, $69.2 \%$; treatment plan, $62.4 \%$; supervision, $60.8 \%$; standardized evaluation, 59.6\%; research paper, 59.4\%; and other evaluation, $52.8 \%$.

For the purpose of reinforcing treatment techniques and developing "hands-on" skills, the following assignments were marked by $>50 \%$ of respondents: equipment or splint construction, $92.5 \%$; lecture, $76.3 \%$; treatment plan, $69.7 \%$; reading, $65.7 \%$; field trip, $59.8 \%$; evaluation, $58.4 \%$; video presentation, $56.4 \%$; standardized evaluation, $51.9 \%$; and progress note, $51.8 \%$. The last purpose listed, developing supervisory or administrative skills, was marked by $>50 \%$ of respondents for the assignments of supervision of another (94.6\%) and administrative project (82.0\%).

Two additional questions asked respondents to state how much they used assignments as either adjunctive and enabling activities or as purposeful, role related activities. Assignments were used as enabling activities, or those used for practice, background, or preparation, frequently by 17 (15.5\%) respondents, occasionally by $56(50.9 \%)$ respondents, and not used by 37 $(33.6 \%)$ respondents. There were 2 missing responses. Assignments were used as puposeful activities, or those related to patient treatment and role of 
therapist, frequently by $96(86.5 \%)$ respondents, occasionally by $14(12.6 \%)$ respondents, and not used by $1(.9 \%)$ respondent. There was 1 missing response to the question.

Question 5: How are didactic assignments relevant to the stated goals of fieldwork education?

This question cannot be answered directly from the data obtained, as respondents did not specify stated goals of fieldwork education. The questionnaire asked respondents to rate on a 5-point scale from essential to unimportant those skills which may be expected of a Level II Fieldwork student at the completion of the fieldwork assignment. Overall, the skills or objectives for fieldwork were rated very highly with at least $66 \%$ of respondents rating moderately important (rating 3) to essential (rating 1) all listed objectives. Six of the total 21 listed objectives had ratings of unimportant (rating 4 or 5 ) greater than $10 \%$.

To simplify the data and to ease comparison in the discussion section the following are a group of objectives which are similar to the purposes used in question number 4 , and the responses given. Assessment and program planning were rated as essential to moderately important by 108 (97.3\%) respondents, with $3(2.7 \%)$ ratings as unimportant and 1 missing response. Problem solving was rated as moderately important to essential by $112(100 \%)$ respondents. Documentation and communication were rated as moderately important to essential by $110(98.2 \%)$ respondents with $2(1.8 \%)$ responses of unimportant. Hands-on treatment was rated as moderately important to essential by $110(98.2 \%)$ respondents with $2(1.8 \%)$ responses of unimportant. Administration was rated as moderately important to essential by $75(67.6 \%)$ 
respondents with $36(32.4 \%)$ responses of unimportant and one missing response. Please see the discussion section for further explanation of this research question.

Question 6: What are the expectations of students for completing work outside the fieldwork setting?

Fieldwork supervisors were asked whether they require students to complete work outside the fieldwork setting at home. Of the $112,92(82.1 \%)$ said yes, and $20(17.9 \%)$ said no. Those who responded yes were then asked to check the type of work expected. Respondents could check more than one response. Table 15 lists the types of work and data obtained. The items to choose from included: independent review of information, reading, planning/preparation, and written assignments/special projects. Forty-three respondents $(46.7 \%)$ checked all the items. Of those who included other types of homework $(n=5)$ the responses included: watching or reviewing audiovisual materials $(n=2)$; and completing any additional work that cannot be completed during work hours, such as progress notes $(n=3)$.

Question 7: How much time do fieldwork supervisors estimate students spend outside of fieldwork time on assignments?

Fieldwork supervisors were asked to estimate the amount of time on average per week that students spend on didactic assignments outside of work hours. Table 16 summarizes the data obtained from this question. Those who had responded that they expect students to complete work at home $(n=92)$ were included, with 90 valid responses and 2 missing responses. Most of the respondents expected that students worked 2-3 hours per week to complete assignments. 
Table 15

Iype of Homework Required of Level IIFieldwork Students

\begin{tabular}{lrr}
\hline Type of Work & n & Percent \\
\hline Independent Review of Information & 74 & 80.4 \\
Reading & 80 & 87.0 \\
Planning/Preparation & 67 & 72.8 \\
Written Assignments/Projects & 72 & 78.3 \\
Other & 5 & 5.4 \\
\hline
\end{tabular}

Table 16

Time Students Spend Outside Work Hours to Complete Assignments $(\underline{n}=92)$

\begin{tabular}{lrr}
\hline Hours per Week & n & Percent \\
\hline $0-1$ & 7 & 7.6 \\
$2-3$ & 50 & 54.3 \\
$4-5$ & 25 & 27.2 \\
$6-7$ & 6 & 6.5 \\
$>7$ & 2 & 2.2
\end{tabular}

Note: Missing Responses $=2$

Median $=2-3$ 


\section{CHAPTER 5}

\section{DISCUSSION, IMPLICATIONS AND RECOMMENDATIONS}

Discussion

The discussion of the data and results is presented in answer to each research question including relevance to the literature and the model of occupational performance, where appropriate.

Question 1: What types of didactic assignments are required of Level II Fieldwork students by fieldwork centers in occupational therapy?

The list of learning experiences from the questionnaire could be separated into three groups. The first are directly patient related, including treatment plan, progress note, evaluation, patient rounds, and equipment construction. These assignments were used by $57-100 \%$ of fieldwork centers and appear most consistently used. The second group are more purely didactic, not necessarily related to patient care, and include case study, notebook, journal, paper, field trip, oral presentation, video, reading, and lecture attendance. These were required by $7-92 \%$ of fieldwork centers. Case study, field trip, and oral presentation were the most commonly required. The last group are also indirect therapy services such as staff conferences, supervision, and administration. Although staff conferences were highly utilized (88.4\%) as learning experiences, supervision and administration were only used by $28.6 \%$ and $33.0 \%$ of centers, respectively. 
The AOTA (1980) made recommendations for using learning assignments which are patient related, direct occupational therapy service as well as indirect service. Scully and Perry (1977) also recommended both patient related as well as administrative, research, and educational activities as learning experiences. It is clear from the data that both types are being used to some degree in Level II Fieldwork with greater variety of indirect assignments, but more consistency with direct patient related tasks.

Case study was mentioned most frequently as a recommended learning activity in the literature (Foley \& Smilansky, 1980; Line, 1969; McPherson, 1976; Neistadt, 1987; and Pelland, 1987) and was found to be very commonly required in Level II Fieldwork. Other recommendations in the literature such as video tapes and role play (Foley \& Smilansky, 1980) were not found to be commonly used. These results are failly consistent with a study conducted by the AOTA in 1963 in which case study, student notebook, reference reading, special project, written paper, and activity analysis were assignments being used by fieldwork centers (AOTA, 1963).

The AOTA has stated that fieldwork centers are very individual in terms of philosophy, characteristics and environment and that this affects the type of available learning experiences (AOTA, 1988). The assignments listed as "other" in Table 3 demonstrate some of the possibilities and variety being used by some settings. It can be seen that some assignments are very facility specific and would not be appropriate or useful in other settings such as videoflouroscopic study or training program in corrections. These are some obvious examples but they may help demonstrate how even subtle differences may affect learning opportunities and outcome. 
It was interesting to note that there were 18 assignments and learning activities listed on the questionnaire, and an additional 23 were listed as additional assignments under "other." There were some interesting and creative assignments listed, many of which were more enabling or didactic learning assignments, but many also were more purposeful, role-related activities.

Question 2: What is the quantity of each of the assignments required of Level II Fieldwork students?

The data show that there is a great range in the quantity of assignments required of Level II Fieldwork students (see Tables 4-11). Several responses reflected variation between students as related to the student and patient population. This contributed to an inability to state the number of required assignments.

The greatest variation occurred for the assignments of evaluation, treatment plan, progress note, patient rounds, and staff conference, which all had a range from 1 time only to daily to 60 times. This raised a question of definition and how much variation occurs between facilities in defining these terms. Standardized evaluation was one assignment which received a response of daily, but the majority (81.7\%) required this learning experience from 1-10 times. Some standardized evaluations require time and effort in order to learn procedures, administration, and scoring and would be very time consuming and difficult for a student to administer daily. Treatment planning may be interpreted as an informal treatment session plan by the student, or may be a more thorough written plan. Likewise, staff conferences could be interpreted as informal student-supervisor meetings or as more organized 
departmental meetings. It is difficult to make generalizations or comparisons based on this variation. It should again be stated, as with Question 1, that facilities vary and this variation can affect the learning opportunities and experiences available to students.

Other assignments showed much less range in responses, but still had some variation. For the following list of assignments $75 \%$ or more of those requiring the assignment had students complete only 1: case study, research paper, administrative project, and supervision assignment. For the remaining assignments which were listed on the questionnaire, the greatest number of respondents (from $31.1-71.4 \%$ ) required only 1 assignment. These include adaptive equipment design, field trip, oral presentation, reading assignment, lecture attendance, and video presentation. The next most common response for each of these assignments, except for lecture attendance, was 2.

It seems that direct patient care areas such as treatment planning and evaluation are used more often, with more of each type required, while indirect service areas and the more purely didactic, enabling activities are used less often. This seems appropriately consistent with the workload of a clinician who works with patients most of the time but does complete additional work and projects as an adjunct. In a study by Llorens and Adams (1978), it was found that occupational therapy students preferred to learn by working with people and with direct experience. This appears to be a characteristic of the assignments used more often during Level II Fieldwork.

Repetition of tasks such as evaluation, treatment planning, note writing, and discussion of patients in team meetings seems important for the student in order to become more comfortable and proficient in these basic tasks. The 
literature stated that the sequence of learning proceeds from simple to complex, and that practicing newly acquired skills is important for learning success (McPherson, 1976). Further, routines and standards need to be learned before creative alternatives can be developed (Cohn, 1989). The occupational performance model is consistent with these ideas and could be used as a model for educating occupational therapy students as students progress through the developmental stage from student to clinician.

Question 3: Is each student at a particular fieldwork center required to complete the same assignments, or is there variation reflecting consideration by fieldwork supervisors of the individual needs and learning styles of students?

Approximately three-fourths of the facilities varied assignment requirements of Level II Fieldwork students based on students' needs, and slightly more than two-thirds varied assignments based on students' learning styles. Of those fieldwork supervisors who allow variation in assignment requirements, the majority (slightly less than two-thirds) involved the student somewhat, retaining more input themselves. Of the remaining one-third, most involved the student to a greater extent, while few ( $<10 \%$ of those responding to the questions) did not involve the student in the choice of assignments.

McPherson (1976) has stated that choice of instructional activities and self-pacing are components of student control, and when learners perceive themselves in control of the learning situation, motivation and relevance of learning are increased. Llorens and Adams (1978) found in a study of learning styles that occupational therapy students preferred learning conditions which permitted seiting their own objectives using feedback to modify goals, working 
independently, and determining their own study plan. While the majority of fieldwork centers permitted choices in assignments and involved students to some extent based on students' needs and learning style $(69.6 \%$ and $64.3 \%$, respectively), there were many fieldwork centers, approximately one-third, which did not.

Question 4: What is the purpose of the didactic assignments required of Level II Fieldwork students?

The list of purposes, or objectives, used for the questionnaire was developed from the AOTA's fieldwork evaluation report (AOTA, 1987), and the entry-level role delineation for occupational therapists (AOTA, 1981). The fieldwork evaluation report examines student performance in the following areas: assessment, planning, treatment, problem solving, and administration/professionalism. The occupational therapy entry-level role delineation includes tasks in the following areas: referral, assessment, program planning, treatment, program discontinuation, service management, continuing education, and public relations.

In a guide for the development of fieldwork objectives, the AOTA (1980) recommended that objectives be consistent with both the entry-level role delineation and the fieldwork performance report. This was attempted for the purposes of this study and the following general purposes were used: research skills/data collection, problem solving/integration, communication skills, treatment techniques, and supervisory/administrative. It was felt that these areas covered most of those listed above, and the tasks could fall into one or more of these areas.

The data show that assignments serve a variety of purposes in fieldwork 
education (see Table 14). Assignments met all purpose areas listed to some degree, but some purposes or objectives were met in large numbers by only a few assignments. For example, supervision and administration were the least frequently marked purpose and in addition only approximately one third of respondents required such assignments. It may have been that if professionalism was included as an additional purpose more of the indirect enabling assignments would have met this objective.

The assignments which were more directly patient care oriented (treatment plan, progress note, evaluation, and patient rounds) more commonly had the purposes of developing problem solving, communication, and treatment skills. The more indirect or enabling assignments such as case study, research paper, field trip, administrative project, reading, and lecture had more varied purposes depending upon the assignment.

The objective of developing research and data collection skills was listed by the majority of respondents ( 56 or more) for the assignments of case study, standardized evaluation, research paper, and reading assignment. This objective was listed by $25-49 \%$ of respondents as one of the purposes for 7 additional assignments.

The development of problem solving skills, communication skills, and treatment techniques were the three objectives most often listed as the purpose for required assignments by respondents. These three objectives were chosen by $>50 \%$ of respondents for almost half the assignments listed, and by $25-49 \%$ of respondents for just under half the assignments.

The goal of Level II Fieldwork is to promote clinical reasoning, professionalism, and help develop a repertoire of assessments and treatment 
interventions (AOTA, 1991). It was apparent from the responses of fieldwork supervisors that these goals are being met through a variety of assignments. It is interesting to note that two of the top purposes for assignments are problemsolving/integration and treatment techniques/hands-on experience.

Question 5: How do didactic assignments relate to the stated goals of fieldwork education?

As stated, this question cannot be directly answered. It was thought that the data would answer this question, but once data were gathered and analyzed, it was clear that this was not the case. Respondents were not asked to state their objectives, but whether they have written fieldwork goals and objectives (which $95.5 \%$ did) and how students were oriented to these objectives. Respondents were then asked to rate a list of skills and objectives on a scale of 1 to 5 as to the degree of importance held by these skills for competence by fieldwork students at the end of the fieldwork experience. Those skills and objectives which were rated as important by respondents may bear on the types of learning experiences used and stressed by them during fieidwork. It cannot be assumed that these are the stated goals of fieldwork. For the most part, all skills and objectives were rated very highly by respondents. Just over two thirds of the skills and objectives were rated as moderately important to essential by at least $90 \%$ of respondents. Administration, public relations, supervision, and quality review had $20-33 \%$ of respondents rating the skill as relatively unimportant. Still, supervision for example was rated by most respondents (38.4\%) as moderately important.

Assessment, program planning, problem solving, documentation, communication with team members, and treatment were rated as essential by 
$67-84 \%$ of respondents. This list is similar to the purposes used for question 4 . As stated earlier, treatment and problem solving do appear to be important and administrative tasks less important to fieldwork supervisors. This seems to agree with the previous question.

Question 6: What are the expectations of students for completing work outside the fieldwork setting?

The majority of fieldwork settings (82.1\%) expected Level II Fieldwork students to complete some work at home outside work hours, but almost $18 \%$ expect no outside work. The types of work included independent review of information, reading, planning/preparation, and written assignments, or special projects. All were required in large numbers, with a small number including other types of assignments. Of the 5 responses to additional assignments, 2 were review of audiovisual information, and 3 were work not completed during work hours, such as progress notes.

For the most part, it appears that students are able to complete all patient related work including evaluation summaries or interpretation, or progress notes during work hours, and independent or self-paced work may be completed outside fieldwork hours. This seems consistent with the goal of fieldwork to provide for the student opportunities to integrate academic knowledge with application skills at higher levels of performance and responsibility (AOTA, 1988). Students should be expected to take some individual responsibility and interest in learning beyond the outlined assignments and minimum requirements. It is not known how much homework is specifically assigned, but it is the most flexible depending upon student needs and learning style. 
Question 7: How much time do fieldwork supervisors estimate students spend outside of fieldwork time on assignments?

Just over half of the fieldwork settings estimate that students spend 2-3 hours per week to complete assignments. The next most common estimate was for 4-5 hours per week (27.8\%). The question asked how much time students spend in completing assignments, but as asked, following a question on the type of work students complete at home, most likely include independent readings or review as well. This question was asked of fieldwork supervisors but should optimally be asked of students who could tally the number of hours as they were spent. Studies of time use during fieldwork education have been conducted, but they related more to productivity and time use during work hours.

\section{Professional Implications and Recommendations}

Occupational therapy fieldwork educators have the responsibility of guiding and helping Level II Fieldwork students make the transition to the role of clinician. There are many components required of the role and many tasks to be accomplished.

The fieldwork educator should understand the goals, process, and tools used in Level II Fieldwork education, especially since fieldwork centers and students vary. The end goals may be the same and should not be compromised. With newer and more varied practice areas in the ever changing health care field, including work hardening, hand therapy, and small private practice facilities, fieldwork educators may need to find creative 
alternatives in fieldwork education to provide learning experiences which progress students to the basic competence of the entry level therapist.

This study found that variablity appeared to be the rule rather than the exception. The study found that routinely, patient related tasks are used often, such as evaluation, treatment planning, progress note writing, and reporting in team meetings or rounds. As these are part of the basic roles of the clinician, these need to be intact skills possessed by the student. The purposes for these assignments are to develop skills in problem solving and integration, treatment techniques, research and data collection, and communication. It is not clear how much integration of occupational therapy theory is considered. Only one setting required an assignment specifically designed to explore the integration of theory into practice.

Indirect services provided by the occupational therapy professional such as research, administrative projects, or service evaluation were not as frequently addressed in terms of learning assignments during Level II Fieldwork education, but were included to some extent. These assignments seemed to have more of a range of purposes and uses. The more indirect goal of professional administrative or supervisory skill was the least frequently stated purpose for assignments. Indirect service tasks should remain a part of fieldwork educaton as recommended by the AOTA (1980) in some form so the student is exposed to these areas of professional experience.

The occupational performance model, used as a frame of reference to guide this study, could be used in guiding fieldwork education. This model is described as one's ability to accomplish the tasks required by his or her role related to his or her developmental stage. The fieldwork student must learn in 
the areas of motor, sensory-integrative, cognitive, psychological, and social functioning to support occupational performance areas and occupational roles.

At earlier stages, enabling activities may be used. These were used occasionally by $51 \%$, and frequently by $15 \%$ of fieldwork supervisors. Each assignment could be examined for the learning it intends to provide, and the goals it intends to achieve. Enabling activities may be primarily expected during academic coursework, while fieldwork supervisors would use fieldwork experiences to develop more purposeful, role related skills. Purposeful activities were used frequently $(86 \%)$ by fieldwork supervisors. Those supervisors who expect more or less enabling activities should examine the needs and learning styles of the students to determine what would be optimal for each student. Most settings explore student learning styles and allow variations in assignments to reflect this, but most supervisors, though collaborative with students, retain most decision making themselves regarding assignment selection.

This study explored learning assignments during Level II Fieldwork, resulting in the following recommendations for continued and further research in this area:

1. To define and clarify didactic assignments used during Level II Fieldwork for comparison with those used during academic coursework.

2. To examine through more subjective and open ended methodology why assignments are used and their purpose in fieldwork education.

3. To explore the use of tools other than didactic assignments used for teaching and learning during Level II Fieldwork education. 
4. To assess student preferences for learning experiences during Level II Fieldwork.

5. To study learning in cognitive, motor, or affective areas through testing and/or observation to compare the effectiveness of different teaching tools, including didactic assignments during Level II Fieldwork.

6. To explore the student workload in terms of patients assigned and the separate role related activities from enabling activities to indirect service task assignments.

7. To explore how students use assignments and patient treatment experiences to integrate occupational therapy theory into practice.

8. To compare learning assignments and requirements used by physical disabilities settings to psychosocial dysfunction settings during Level II Fieldwork. 


\section{REFERENCES}

Ackley, N. (1960). From the committee on student affiliation. The American Journal of Occupational Therapy, 14, 151-156.

Agriesti-Johnson, C. (1978). Early exposure and first-level experience. In C.

Ford (Ed.), Clinical education for the allied health professionals (pp. 69-

78). St. Louis: C. V. Mosby.

American Occupational Therapy Association. (1928). Report of the committee

on teaching methods. Qccupational Therapy and Rehabilitation, $Z$, 287-300.

American Occupational Therapy Association. (1935). Report of the methods of teaching committee. Occupational Therapy and Rehabilitation, 14, 421-423.

American Occupational Therapy Association. (1939). Report of the committee on education. eccupational Therapk and Rehabilitation, 18, 51-54.

American Occupational Therapy Association. (1963). Occupational therapy curriculum study. New York: AOTA.

American Occupational Therapy Association. (1974). A curriculum guide for eccupational therapy educators. Rockville, MD: AOTA.

American Occupational Therapy Association. (1980). Guide to the preparation of fieldwork objectives for occupational therapy students. The American Journal of Occupational Therapy, 34, 119-125.

American Occupational Therapy Association. (1981). Entry-level role delineation for OTRs and COTAs. In AOTA, Guide to fieldwork education (pp, 77-88). Rockville, MD: AOTA. 
American Occupational Therapy Association. (1983). Essentials and guidelines of an accredited educational program for the occupational therapist. The American Journal of Occupational Therapy, 37, 817-823. American Occupational Therapy Association. (1987). The AOTA, Inc. fieldwork evaluation for the occupational therapist. In AOTA, Guide to fieldwork education (pp. 124-131). Rockville, MD: AOTA.

American Occupational Therapy Association. (1988). Guide to fieldwork education. Rockville, MD: AOTA.

American Occupational Therapy Association. (1991). Essentials and quidelines for an accredited educational program for the occupational therapist. Unpublished manuscript.

Barris, R., Kielhofner, G., \& Bauer, D. (1985). Learning preferences, values, and student satisfaction. Journal of Allied Health, 14, 13-23.

Barrows, H. S. (1986). The scope of clinical education. Journal of Medical Education, 61(9), 23-33.

Christie, B. A., Joyce, P. C., \& Moeller, P. L. (1985a). Fieldwork experience, part I: Impact on practice preference. The American Jeurnal of Occupational Therapy, 39, 671-674.

Christie, B. A., Joyce, P. C., \& Moeller, P. L. (1985b). Fieldwork experience, part II: The supervisor's dilemma. The American Journal of Occupational Therapy, 39, 675-681.

Cohn, E. S. (1988). Fieldwork education: Applying theory to practice. In H. L. Hopkins \& H. D. Smith (Eds.), Willard and Spackman's occupational therapy (pp. 9-15). Philadelphia: J. B. Lippincott. 
Cohn, E. S. (1989). Fieldwork education: Shaping a foundation for clinical reasoning. The American Journal of Occupational Therapy, 43, 240-244.

Cohn, E. S. \& Frum, D. C. (1988). Fieldwork supervision: More education is warranted. The American Journal of Occupational Therapy, 42, 325-327.

Colman, W. (1990). Evolving educational practices in occupational therapy: The War Emergency Courses, 1936-1954. The American Journal of eccupational Therapy, 44, 1028-1036.

Crist, P. H. \& Cooper, R. G. (1988). Evaluating clinical competence with the new fieldwork evaluation. The American Jeurnal of Qccupational Therapy, 42, $771-773$.

Dunton, W. R., Jr. (1921). The passing of the Henry B. Flaville School. Maryland Psychiatric Quarterly, 10, 77-79.

Emery, M. J. (1984). Effectiveness of the clinical instructor: Students' perspective. Physical Therapy, 64, 1079-1083.

Fidler, G. (1966). Learning as a growth process: A conceptual framework for professional education. The American Journal of Occupational Therapy, 20, 1-8.

Foley, R. P. \& Smilansky, J. (1980). Ieaching techniques: A handbook for health professionals. New York: McGraw-Hill.

Ford, C. W. (1978). A place to begin: A systems approach to clinical education. In C. W. Ford (Ed.), Clinical education for the allied health professionals (prologue). St. Louis: C. V. Mosby.

Gill, A., Marmo, N., \& Shuster, J. (1978). The effectiveness of laboratory versus written examinations in an anatomy course. The American Journal of Occupational Therapy, 32, 26-30. 
Hopkins, H. L. (1988). An historical perspective on occupational therapy.

In H. L. Hopkins \& H. D. Smith (Eds.), Willard and Spackman's eccupational therapy (pp. 16-37). Philadelphia: J. B. Lippincott.

Irby, D. M. (1978). Clinical faculty development. In C. W. Ford (Ed.), Clinical education for the allied health professionals (pp. 95-105). St. Louis: C. V. Mosby.

Kahmann, W. (1942). New trends in the schools of occupational therapy and clinical training. Occupational Therapy and Rehabilitation, 21, 214-218.

Kautzmann, L. N. (1990). Clinical teaching: Fieldwork supervisors' attitudes and values. The American Journal of Occupational Therapy, 44, 835-838.

Kidner, T. B. (1928). Professional training in occupational therapy. Psychiatric Quarterly, 2, 184-188.

Leonardelli, C. A. \& Gratz, R. R. (1986). Occupational therapy education: The relationship of purpose, objectives, and teaching models. The American Journal of Occupational Therapy, 40, 96-102.

Line, J. (1969). Case method as a scientific form of clinical thinking. The American Journal of Occupational Therapy, 23, 308-313.

Llorens, L. A. \& Adams, S. P. (1978). Learning style preferences of occupational therapy students. The American Journal of Occupational Therapy, 32, 161-164.

Loomis, B. (1992). The Henry B. Flavill School of Occupations and Eleanor Clarke Slagle. The American Journal of Occupational Therapy, 46, 34-37. McPherson, A. (1976). Methods and materials. In C. W. Ford (Ed.), Ieaching in the health professions (pp. 148-157). St Louis: C. V. Mosby. 
Meyers, S. K. (1989). Program evaluations of occupational therapy level II fieldwork environments: A naturalistic inquiry. Occupational Therapy Journal of Research, 2, 347-361.

Neistadt, M. E. (1987). Classroom as clinic: A model for teaching clinical reasoning in occupational therapy education. The American Jeurnal of Eccupational Therapy, 41, 631-637.

Parham, D. (1987). Toward professionalism: The reflective therapist. The American Journal of Occupational Therapx, 41, 555-561.

Pascoe, J. A. (1987). An investigation of the resources used for the preparation of the occupational therapy fieldwork educator and the Level II Fieldwork education program. Unpublished master's thesis, San Jose State University, San Jose, CA.

Patel, V. L. \& Cranton, P. A. (1983). Transfer of student learning in medical education. Jeurnal of Medical Education, 58, 126-135.

Pedretti, L. W. \& Pasquinelli, S. (1990). A frame of reference for occupational therapy in physical dysfunction. In Pedretti, L. W. \& Zoltan, B. (Eds.), Qccupational therapy practice skills for physical dysfunction (pp.1-17). St Louis: C. V. Mosby.

Pelland, M. J. (1987). A conceptual model for the instruction and supervision of treatment planning. The American Journal of Occupational Therapy, 41, 351-359.

Presseller, S. (1983). Fieldwork education: The proving ground of the profession. The American Jeurnal of Occupational Therapy, 37, 163-165.

Rogers, J. C. \& Hill, D. J. (1980). Learning style preferences of bachelor's and master's students in occupational therapy. The American Journal of 
Occupational Therapx, 34, 789-793.

Schwartz, K. B. (1984). An approach to supervision of students on fieldwork. The American Journal of Occupational Therapy, 38, 393-397.

Scully, R. M. \& Perry, J. (1977). Overview of the workshop on unique aspects of clinical education. In J. Perry (Ed.), Handbook of clinical faculty development (pp. 103-115). North Carolina: University of NC.

Scully, R. M. \& Shepard, K. F. (1983). Clinical teaching in physical therapy education: An ethnographic study. Physical Therapy, 63, 349-358.

Spackman, C. S. (1953). Evaluation of clinical practice programs for occupational therapy students. The American Journal of Occupational Therapy, Z, 210-211.

Windom, P. A. (1982). Developing a clinical education program from the clinician's perspective. Physical Therapy, 62, 1604-1609. 
APPENDIX A

QUESTIONNAIRE 
Questionnaire

A. Demographic Information

1. Present position.

Manager

_- Supervisor

- Senior Therapist/Occupational Therapist II

_ Staff Therapist

_ Other (please specify)

2. Highest degree obtained.

BS/BA

MS/MA

$\mathrm{PhD} / \mathrm{Ed} . \mathrm{D} / \mathrm{D} . \mathrm{Sc} / \mathrm{other}$ doctorate

Other (please specify)

3. Years as a Registered Occupational Therapist.

years

4. Years as a fieldwork supervisor.

years

5. Person with primary responsibility for planning Level II

Fieldwork at your facility.

- Occupational Therapy Manager/Director

_ Fieldwork Supervisor

- Fieldwork Coordinator

- Staff Occupational Therapist(s)

_ Other (please specify)

6. Person with primary responsibility for supervising Level II Fieldwork students at your facility.

- Occupational Therapy Manager/Director

_ Fieldwork Supervisor

_ Fieldwork Coordinator

- Staff Occupational Therapist(s)

_ Other (please specify)

7. Patient bed capacity or caseload at your facility. patients/beds 
8. Major area of practice used for the purposes of Level II Fieldwork education. Mark only one.

- Psychosocial Dysfunction

_ Physical Disabilities

_ Other (please specify)

\section{B. Learning Experiences}

9. Please check all those learning experiences which you use with Level II Fieldwork students, then indicate the number of each required of one student during one fieldwork placement.

Learning Experiences Number

$$
\text { case study }
$$

_ treatment plan

progress note

standardized evaluation

other evaluation

adaptive equipment design

(include splints)

student notebook

journal

research paper

field trip

patient rounds

staff conferences

oral presentation

administrative project

supervision of another

video presentation

reading assignments

lectures attended

other (please list all other assignments required and the number)

10. Do you have Level II Fieldwork students do some work at home outside of the fieldwork setting?

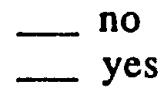


11. If you answered yes to the previous question, what type of work do you expect students to complete during their individual time?

Check all that apply.

- independent review of information

_ reading

_- planning/preparation

_ writton assignments/special projects other (please specify)

12. If you answered yes to question 10 , please estimate the amount of individual time students spend per week outside of the fieldwork time to complete assignments.

$0-1$ hours per week

2-3 hours per week

4-5 hours per week

6-7 hours per week

greater than 7 hours per week

13. Do you typically vary the type and/or number of assignments depending on the individual needs of students?

- no

- yes

14. If you answered yes to the previous question, do you involve students in the selection of assignments?

yes, the student collaborates on all or most assignment choices

yes, the student collaborates on several assignment choices no, the assignments are determined by the fieldwork supervisor

15. Do you typically vary the type and/or number of assignments depending on the individual learning style of students?

- no

16. If you answered yes to the previous question, do you involve students in the selection of assignments?

yes, the student collaborates on all or most assignments

- yes, the student collaborates on several assignment choices

- no, the assignments are determined by the fieldwork supervisor 
17. Do you explore each student's learning preferences through information or discussion obtained from the student? yes no

18. Do you have written fieldwork goals and/or objectives for Level II Fieldwork?<smiles>C[As](C)(=O)O</smiles>

19. If you answered yes to question 18 , how are students oriented specifically to these objectives? student manual, which is available to students separate written list of objectives

- through discussion with fieldwork supervisor

_ students are not specifically oriented

20. The following is a list of skills/objectives which may be expected of a Level II Fieldwork student. Please rate each from 1 to $5 \quad(1=$ an essential skill, $3=$ moderately needed skill, $5=$ an unimportant skill) circling the corresponding number.

$\begin{array}{llllll}\text { screening } & 1 & 2 & 3 & 4 & 5 \\ \text { assessment } & 1 & 2 & 3 & 4 & 5 \\ \quad & 1 & 2 & 3 & 4 & 5 \\ \text { interview } & 1 & 2 & 3 & 4 & 5 \\ \begin{array}{l}\text { observation } \\ \text { standardized evaluation }\end{array} & 1 & 2 & 3 & 4 & 5 \\ \begin{array}{l}\text { non-standardized } \\ \text { evaluation techniques }\end{array} & 1 & 2 & 3 & 4 & 5 \\ \text { review of medical record } & 1 & 2 & 3 & 4 & 5\end{array}$


(Question 20 continued) The following is a list of skills/objectives which may be expected of a Level II Fieldwork student. Please rate each from 1 to 5 ( $1=$ an essential skill, $3=$ moderately needed skill, $5=$ an unimportant skill) circling the corresponding number.

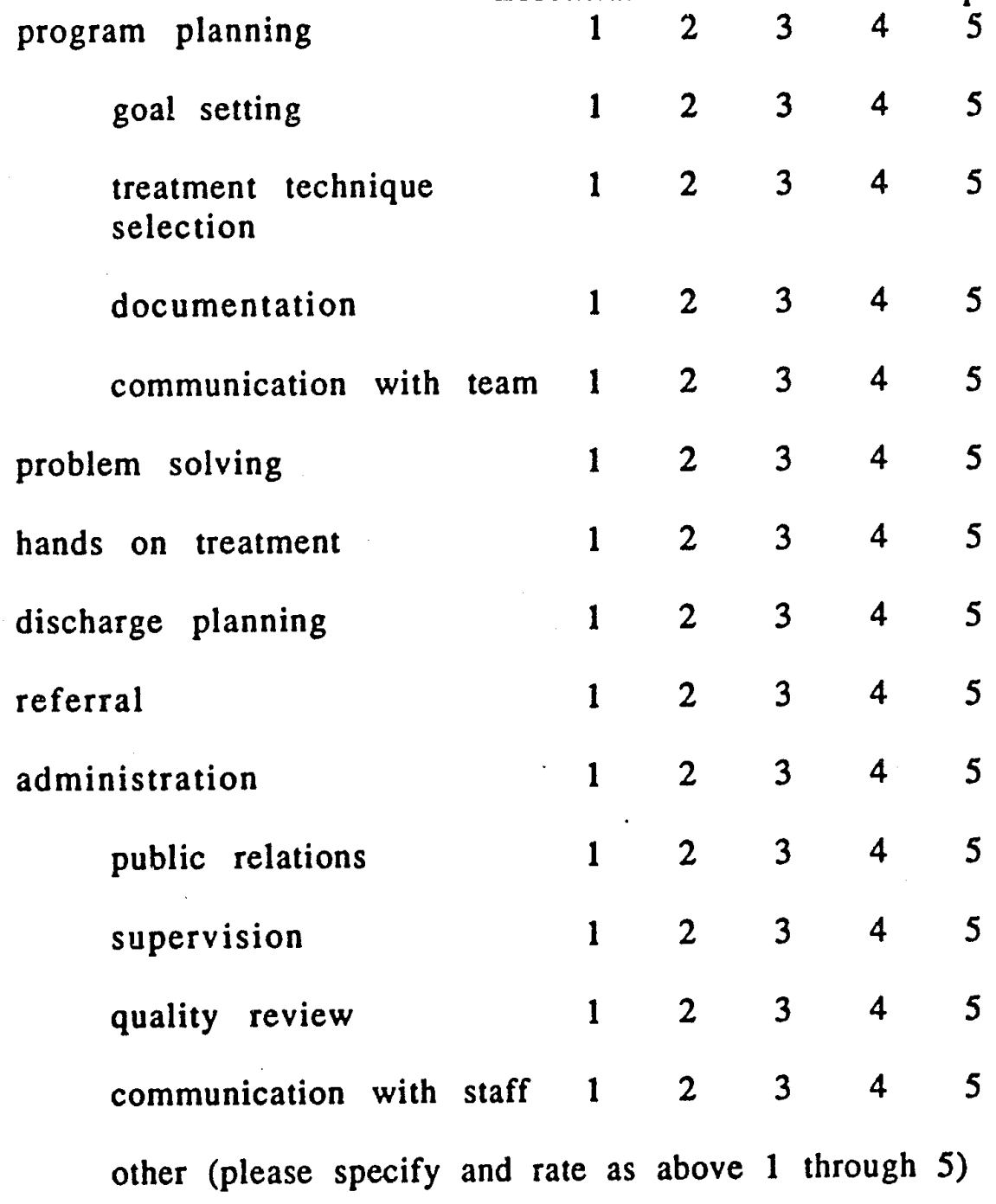


21. For the following list of didactic assignments, please check the purpose of each.

\begin{tabular}{|c|c|c|c|c|c|}
\hline assignment : & 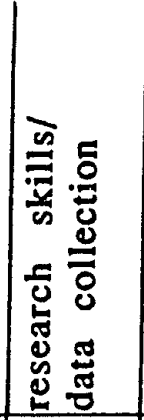 & 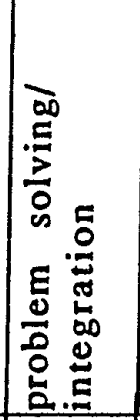 & 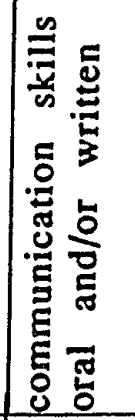 & 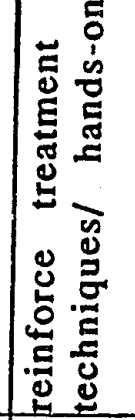 & 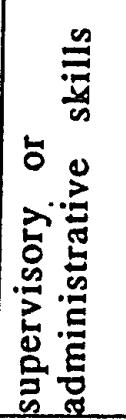 \\
\hline \multicolumn{6}{|l|}{ case study: } \\
\hline \multicolumn{6}{|l|}{ treatment plan: } \\
\hline \multicolumn{6}{|l|}{ progress note: } \\
\hline \multicolumn{6}{|l|}{ formalized evaluation: } \\
\hline \multicolumn{6}{|l|}{ other evaluation: } \\
\hline \multicolumn{6}{|l|}{ splint/adaptive equipment design: } \\
\hline \multicolumn{6}{|l|}{ student notebook: } \\
\hline \multicolumn{6}{|l|}{ research paper: } \\
\hline \multicolumn{6}{|l|}{ field trip: } \\
\hline \multicolumn{6}{|l|}{ patient rounds: } \\
\hline \multicolumn{6}{|l|}{ staff conferences: } \\
\hline \multicolumn{6}{|l|}{ oral presentation: } \\
\hline \multicolumn{6}{|l|}{ administrative project: } \\
\hline \multicolumn{6}{|l|}{ supervision of another: } \\
\hline \multicolumn{6}{|l|}{ video presentation: } \\
\hline \multicolumn{6}{|l|}{ reading assignments: } \\
\hline lectures attended: & & & & & \\
\hline
\end{tabular}


other (please list all other asignments required at your facility):

22. Do you use assignments as adjunctive or enabling activities which may be for practice, background, or preparation? For example, a case study based on a "textbook" patient, practice progress notes not included in the medical chart, or a vocabulary list. no

_ yes, used occasionally

_ yes, used frequently

23. Do you use assignments as purposeful, role performance activities which are treatment and therapist oriented? For example, treatment plan is included in the medical chart, or used as part of the treatment program. no

_ yes, used occasionally

_ yes, used frequently 
APPENDIX B

COVER/CONSENT LETTER 
February 3, 1992

\section{Dear Fieldwork Coordinator,}

I am a graduate student in Occupational Therapy at San Jose State University, conducting a study investigating learning tasks, or didactic assignments, and their purpose during Level II Fieldwork. I would like to ask for your participation. The results of this study should further our understanding of the current uses of learning assignments during fieldwork, and their relationship to the educational goals of fieldwork.

The participants for this study were chosen from the list of fieldwork centers affiliated with San Jose State. Enclosed is a questionnaire about the use and purpose of Level II Fieldwork assignments. Would you please spend 20 minutes to complete the form and mail it to me by February 28, 1992. The questionnaire should be completed by the fieldwork coordinator, fieldwork supervisor, and if not, a staff therapist who has supervised Occupational Therapy Level II Fieldwork students. Please foward the questionnaire to the appropriate person, if needed.

Your participation in this study is voluntary and the results will remain confidential. The questionnaire will not be associated with your name or institution in any way. The results may be presented at professional conferences or literature. I hope you contribute your valuable information and experience to this study. Failure to participate will not affect your relationship with San Jose State University or the Department of Occupational Therapy. If you have any questions please feel free to call me at (415) 637-9011, or my advisor Jean Still at (408) 924-3078. For questions or complaints regarding research subjects rights, contact Serena Stanford, Associate Academic VicePresident for Graduate Studies and Research, at (408) 924-2480. Thank you for your time and cooperation.

Sincerely,

Karin Boyce

Graduate Student 
APPENDIX C

FOLLOW-UP LETTER 
A cempus of the Callomia State Univorsty

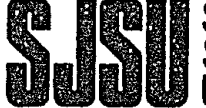

College of Applied Sclences and Arts - Department of Occupational Therapy

One Washington Square • San José, California 95192-0059

Main Office: 408/924-3070 - Fieldwork Office: 408/924-3078 • FAX: 408/924-3088

1149 Woodland Ave

San Carlos, CA 94070

February 17, 1992

Dear Fieldwork Coordinator,

A questionnaire on Level II Fieldwork assignments and educational goals of fieldwork was recently mailed to you at your facility. The questionnaire is to be used in research for a masters thesis in occupational therapy at San Jose State University. The success of this study and pool of information available to the profession depends on your participation and responses to the questionnaire.

It would be greatly appreciated if you would complete the questionnaire and return it by February 28,1992 . If you have done so, please disregard this request and thank you for your time and information. If you have not received the questionnaire and wish to participate in the study, or if you have any questions please call me at (415) 637-9011.

Thank you.

Sincerely,

Karin Boyce 